\title{
Sleep and Memory Consolidation Dysfunction in Psychiatric Disorders: Evidence for the Involvement of Extracellular Matrix Molecules
}

\author{
Barbara Gisabella, Jobin Babu, Jake Valeri, Lindsay Rexrode and Harry Pantazopoulos* \\ Department of Neurobiology and Anatomical Sciences, University of Mississippi Medical Center, Jackson, MS, United States
}

Sleep disturbances and memory dysfunction are key characteristics across psychiatric disorders. Recent advances have revealed insight into the role of sleep in memory consolidation, pointing to key overlap between memory consolidation processes and

OPEN ACCESS

Edited by:

Katherine Conant,

Georgetown University Medical

Center, United States

Reviewed by:

Tomiki Sumiyoshi,

National Center of Neurology

and Psychiatry, Japan

Sara J. Aton,

University of Michigan, United States

*Correspondence:

Harry Pantazopoulos

cpantazopoulos@umc.edu

Specialty section:

This article was submitted to

Neuropharmacology,

a section of the journal

Frontiers in Neuroscience

Received: 27 December 2020

Accepted: 22 April 2021

Published: 14 May 2021

Citation:

Gisabella B, Babu J, Valeri J,

Rexrode $\mathrm{L}$ and Pantazopoulos $\mathrm{H}$

(2021) Sleep and Memory

Consolidation Dysfunction

in Psychiatric Disorders: Evidence for the Involvement of Extracellular

Matrix Molecules.

Front. Neurosci. 15:646678. doi: 10.3389/fnins.2021.646678 structural and molecular abnormalities in psychiatric disorders. Ongoing research regarding the molecular mechanisms involved in memory consolidation has the potential to identify therapeutic targets for memory dysfunction in psychiatric disorders and aging. Recent evidence from our group and others points to extracellular matrix molecules, including chondroitin sulfate proteoglycans and their endogenous proteases, as molecules that may underlie synaptic dysfunction in psychiatric disorders and memory consolidation during sleep. These molecules may provide a therapeutic targets for decreasing strength of reward memories in addiction and traumatic memories in PTSD, as well as restoring deficits in memory consolidation in schizophrenia and aging. We review the evidence for sleep and memory consolidation dysfunction in psychiatric disorders and aging in the context of current evidence pointing to the involvement of extracellular matrix molecules in these processes.

\footnotetext{
Keywords: extracellular matrix, memory consolidation, schizophrenia, bipolar disorder, PTSD, aging, Alzheimer's disease, addiction
}

\section{INTRODUCTION}

Sleep and circadian rhythm disturbances are emerging as shared features across psychiatric disorders and aging, and are strongly associated with memory consolidation and synaptic dysfunction. Recent studies into the structural and molecular processes of memory consolidation during sleep highlight a large degree of overlap with molecular pathways observed in psychiatric disorders, pointing to the potential of these processes as therapeutic targets for memory dysfunction in psychiatric disorders and aging. Extracellular matrix molecules are critically involved in several of the processes implicated in memory consolidation, and are implicated in psychiatric disorders. Recent work from our group and others points to the involvement of the extracellular matrix in synaptic regulation during sleep. We review the current evidence for sleep and memory consolidation dysfunction in psychiatric disorders and aging, in the context of the potential extracellular matrix molecules as a key molecules in memory consolidation dysfunction. 


\section{SLEEP AND MEMORY CONSOLIDATION}

The concept that memory is strengthened during sleep has existed for centuries, at least since early descriptions from the Roman scholar Quintilian, who observed improved memory after sleep (Butler, 1921). The formal concept of memory consolidation was first introduced by Muñller and Pilzecker who introduced the term 'consolidation' to describe the process by which memory is strengthened over time, rather than forming as instant permanent memories (Muller and Pilzecker, 1900). In 1924, the seminal work by Jenkins and Dellenbach (1924) was the first formal study demonstrating memory consolidation during sleep, reporting improved declarative memory for nonsense word syllables after sleep. Modern advances in techniques have allowed for a broad range of studies that provide insight into the potential mechanisms behind memory consolidation during sleep. Collectively, these studies have resulted in the emergence of several current, partially complementary theories regarding the process of memory consolidation.

\section{Current Concepts of Memory Consolidation}

A growing collection of studies from Tononi and Cirelli have established the synaptic homeostasis hypothesis of sleep (Tononi and Cirelli, 2006, 2014). This hypothesis proposes that neurons form and strengthen new synapses during wakefulness, as organisms interact with their environment and encode new memories. In this manner, neurons potentiate synapses during wakefulness in response to environmental inputs, and environmental interactions provide feedback regarding the accuracy of these synapses. During sleep, when the active encoding process is offline, synapses are downscaled, in order to enhance the signal to noise ratio, thus improving memory function (Tononi and Cirelli, 2006, 2014). Several studies supporting this concept have reported decreased dendritic spines and synapses during sleep in sensory and motor cortical regions in rodents (Maret et al., 2011; de Vivo et al., 2017), as well as in the drosophila brain (Gilestro et al., 2009; Bushey et al., 2011) and gene expression changes in pathways involved in synaptic downscaling during sleep (Cirelli, 2005). A growing number of recent studies suggest that synaptic downscaling occurs specifically during REM sleep (Li et al., 2017; Zhou et al., 2020). The firing rates of fast-firing inhibitory neurons expressing the calcium binding protein parvalbumin increases during REM sleep (Niethard et al., 2016), possibly contributing to synaptic downscaling by increasing inhibitory tone.

Despite the evidence for synaptic downscaling, an increasing number of studies suggest that sleep is also important for strengthening specific synapses (Vecsey et al., 2009; Yang et al., 2014; Havekes et al., 2016). Evidence that sleep deprivation impairs memory strength (Vecsey et al., 2009), and results in decreased hippocampal dendritic spines (Havekes et al., 2016), supports the hypothesis that selective synapses are strengthened during sleep. Furthermore, sleep deprivation results in decreases of dendritic spines (Raven et al., 2019) as well as the number of granule cells expressing the immediate early gene Arc in the mouse dentate gyrus (Delorme et al., 2019). However, a recent electron microscopy study reporting increased synaptic density and axon-spine interface in the hippocampus of sleep deprived mice (Spano et al., 2019) points to synaptic downscaling in the hippocampus. These discrepancies may be due in part to region and branch specific regulation of dendritic spines during sleep. Our recent study in the CA1 hippocampal area showing branch specific changes in dendritic spines following sleep deprivation (Gisabella et al., 2020) provides support for this branch and region specific regulation. Further support comes from a live imaging study of dendritic spines in the motor cortex. This work demonstrates that sleep promotes dendritic spine formation of motor memory in selective branches of layer V motor cortex neurons (Yang et al., 2014), These studies support the hypothesis that sleep is involved in strengthening selective synapses formed during wakefulness for selective memories, and this occurs even in cortical areas where net synaptic downscaling during sleep has been reported (Maret et al., 2011; de Vivo et al., 2017). Such discrepancies have also been proposed to arise from methodological differences, particularly differences in sleep deprivation methods (Havekes and Aton, 2020). An extensive review of mouse sleep deprivation studies highlights the role of novelty exposure in sleep deprivation methods as a potential major methodological difference contributing to discrepancies in synaptic downscaling or upscaling findings following sleep deprivation (Havekes and Aton, 2020). Differences in circadian time of sampling as well as sex differences are also proposed to contribute to these discrepancies between studies (Havekes and Aton, 2020).

In summary, evidence suggests that while sleep results in a net reduction of synapses in certain brain regions, specific synapses in these regions are selectively potentiated during sleep. Furthermore, this net loss of synapses in sensory and motor cortical areas may not apply to all brain regions. A current theory by Rasch and Born proposes that certain synapses formed during the day are tagged by specific proteins that indicate these synapses will be strengthened during sleep, whereas other synapses are pruned as memory storage is reorganized (Rasch and Born, 2013; Dudai et al., 2015). According to this theory, memories are reorganized during slow wave sleep in a process called systemic consolidation (Rasch and Born, 2013; Dudai et al., 2015). In systemic consolidation, memory representations are reactivated, and transferred from short-term storage sites such as the hippocampus, to long-term storage in neocortical areas and integrated into existing knowledge schemas (Rasch and Born, 2013; Dudai et al., 2015). Memories are then strengthened in these long-term storage areas during REM sleep, in a process called synaptic consolidation, while the short-term storage memories are removed via synaptic pruning (Rasch and Born, 2013; Dudai et al., 2015). An increasing number of studies have shown that neuronal network activation in the hippocampus during spatial learning is replayed in the same sequence during sleep, particularly during slow wave sleep (Pavlides and Winson, 1989; Wilson and McNaughton, 1994; Skaggs and McNaughton, 1996; Kudrimoti et al., 1999; Poe et al., 2000; Bendor and Wilson, 2012). Hippocampus-guided neuronal network replay during sleep has now been reported in several brain regions, including 
the striatum (Lansink et al., 2009) and the medial prefrontal cortex (Euston et al., 2007). These studies provide support for the theory of systemic consolidation during slow wave sleep. Further support for this hypothesis comes from animal studies showing that newly formed memories become independent of the hippocampus faster and are more stable when associated with pre-existing neocortical schema (Tse et al., 2007; Tse et al., 2011).

Which synapses are strengthened during sleep, and how they are distinguished from synapses that are downscaled? Growing evidence suggests that certain synapses are tagged in an activity dependent manner. During sleep, while encoding is offline, memories tagged during wakefulness can be consolidated through systemic consolidation and synaptic consolidation, whereas non-tagged synapses can be pruned, greatly reducing the signal to noise ratio and restoring the capacity to form new synapses (Benchenane et al., 2010; Inostroza and Born, 2013). The level of coherence in theta frequency in networks involved in formation of specific memories during encoding has been proposed to be associated with tagging selective memories during wakefulness to be consolidated during sleep (Benchenane et al., 2010; Inostroza and Born, 2013). Studies discussed below provide some insight into the potential molecular mechanisms behind these proposed memory consolidation processes.

\section{Molecular Mechanisms of Memory Consolidation}

Long-term plasticity (LTP) has been proposed to be associated with local tagging of synapses (Frey and Morris, 1997). These tags capture synthesized plasticity related proteins at selective dendritic spines, which allow for stabilization of these spines (Redondo and Morris, 2011). CamKII dependent remodeling of the actin cytoskeleton in dendritic spines is an essential feature for synaptic tagging for memory enhancement (Ramachandran and Frey, 2009; Redondo et al., 2010). The proposed molecular mechanisms of synaptic tagging for memory consolidation during sleep may differ from the mechanisms described for memory enhancement during wakefulness. Dopaminergic signaling, implicated in several psychiatric disorders (Laruelle et al., 1999; Abi-Dargham et al., 2000; Berke and Hyman, 2000; Hyman and Malenka, 2001; Volkow et al., 2004; Tremblay et al., 2005; Volkow et al., 2006; Abi-Dargham et al., 2009; Cousins et al., 2009; Anand et al., 2011; Belujon and Grace, 2017; Pizzagalli et al., 2019), may contribute to tagging memories for subsequent consolidation during sleep. Increased activation of dopaminergic reward circuits results in enhanced memory reactivation during slow wave sleep in rodents (Gomperts et al., 2015), and enhanced memory consolidation in humans (Feld et al., 2014).

FOXO6 is a transcription factor expressed in the hippocampus (Jacobs et al., 2003; Hoekman et al., 2006; Salih et al., 2012), as well as the amygdala and cortex (Salih et al., 2012), and is implicated in memory consolidation (Salih et al., 2012). FOXO6 knockout mice show selective impairments in contextual and object recognition memory, together with decreased density of dendritic spines in CA1 of the hippocampus (Salih et al., 2012). Furthermore, these mice display altered hippocampal theta wave frequencies during exploration of novel objects, suggesting decreased synchronization of neurons during exploration (Salih et al., 2012). A deficit in decreased synchronization may indicate decreased synaptic tagging, contributing to subsequent memory consolidation deficits (Benchenane et al., 2010; Inostroza and Born, 2013).

The immediate early gene Arc is another marker located in dendritic spines, particularly in sites of increased postsynaptic activity (Steward et al., 1998). Arc knockout mice have normal short term memory, together with impaired long-term memory consolidation (Plath et al., 2006). Furthermore, amygdala specific knockdown of Arc blocks fear memory consolidation (Ploski et al., 2008). In turn, Arc mutant mice display deficits in LTP and LTD (Nikolaienko et al., 2018). Sleep deprivation results in brain region specific changes in Arc expression in the mouse brain (Delorme et al., 2019), providing further support for a complex role in the regulation of synaptic plasticity during sleep. Recent studies have identified Homerla as a potential tag for synaptic pruning during sleep (Diering et al., 2017). Homerla signaling through metabotropic glutamate receptors was shown to be necessary for synaptic downscaling during sleep (Diering et al., 2017). Furthermore, sleep deprivation has been shown recently to cause increased phagocytosis of dendritic spines by astrocytes, together with increased activation of microglia (Bellesi et al., 2017). This enhanced spine elimination during sleep deprivation may reflect mechanistic processes that are also involved in synaptic downscaling during sleep at a less pronounced level.

\section{Extracellular Matrix: Evidence for Involvement in Memory Consolidation}

Extracellular matrix molecules (ECM) interact with many of the synaptic regulation processes described above, and a growing amount of evidence points to the involvement of ECMs in memory consolidation (Table 1). Chondroitin sulfate proteoglycans (CSPGs) are a family of ECMs that are critically involved in a range of neurodevelopmental and adult functions (Dobbertin et al., 2003; Garwood et al., 2003; Wu et al., 2004; Maeda et al., 2010; Maeda et al., 2011). In late postnatal development, these molecules contribute to the formation of perineuronal nets (PNNs) (Figure 1), ECM structures that surround subpopulations of neurons, first described by Camillo Golgi in 1898 (Golgi, 1989). Work over the past several decades has elucidated the critical role of these structures in a broad range of processes, including synaptic plasticity and regulation of electrophysiological properties (Kalb and Hockfield, 1988; Sugiyama et al., 2008; Gogolla et al., 2009). PNNs are involved in regulating several functional neuronal properties, including somatic inhibition, glutamate receptor trafficking, and synaptic stabilization (Pizzorusso et al., 2002; Frischknecht et al., 2009; Frischknecht and Gundelfinger, 2012; Carceller et al., 2020; Christensen et al., 2021). For example, removal of PNNs decreases densities of inhibitory and excitatory synapses on the soma of PVB neurons (Carceller et al., 2020), reduces gamma activity (Christensen et al., 2021), and de-stabilizes the grid cell network (Christensen et al., 2021). Several studies, including seminal work in the visual cortex and the amygdala, demonstrated that PNNs form during the end of critical periods 
TABLE 1 | Evidence for ECM molecules in sleep and memory consolidation processes.

\begin{tabular}{|c|c|}
\hline Reference & Summary of Findings \\
\hline Taishi et al., 2001 & $\begin{array}{l}\text { Sleep deprivation results in decreased mRNA expression } \\
\text { and enzymatic activity of MMP-9 }\end{array}$ \\
\hline $\begin{array}{l}\text { Szklarczyk et al., } \\
2002\end{array}$ & $\begin{array}{l}\text { Dendritic spine remodeling coincides with increased } \\
\text { MMP-9 expression }\end{array}$ \\
\hline Nagy et al., 2006 & $\begin{array}{l}\text { MMP-9 expression is crucial in late-stage LTP and } \\
\text { hippocampal-dependent memory }\end{array}$ \\
\hline Nagy et al., 2007 & $\begin{array}{l}\text { Disrupted MMP-3 and MMP-9 activity in the hippocampus } \\
\text { causes avoidance learning impairments }\end{array}$ \\
\hline Brown et al., 2009 & $\begin{array}{l}\text { Pharmacological disruption of MMP activity results in } \\
\text { disruption of fear memory reconsolidation }\end{array}$ \\
\hline $\begin{array}{l}\text { Beurdeley et al., } \\
2012\end{array}$ & $\begin{array}{l}\text { Inhibition of OTX2 and PNN binding enhances synaptic } \\
\text { plasticity and reduces PNN and PVB expression }\end{array}$ \\
\hline $\begin{array}{l}\text { Hayashi et al., } \\
2013 a\end{array}$ & $\begin{array}{l}\text { Cathepsin-S KO mice lack diurnal rhythms in dendritic } \\
\text { spine density }\end{array}$ \\
\hline $\begin{array}{l}\text { Niethard et al., } \\
2016\end{array}$ & $\begin{array}{l}\text { Increased PVB neuron firing rates are accompanied by } \\
\text { decreased pyramidal neuron activity during REM sleep }\end{array}$ \\
\hline $\begin{array}{l}\text { Harkness et al., } \\
2019\end{array}$ & $\begin{array}{l}\text { PNN composition is increased in the prelimbic cortex of } \\
\text { sleep-deprived rats, suggesting that PNN composition } \\
\text { decreases during sleep }\end{array}$ \\
\hline Shi et al., 2019 & $\begin{array}{l}\text { PNN degradation contributes to GABAergic inhibition on } \\
\text { hippocampal pyramidal neurons, contributing to LTP and } \\
\text { memory consolidation impairment }\end{array}$ \\
\hline $\begin{array}{l}\text { Delorme J. et al., } \\
2020\end{array}$ & $\begin{array}{l}\text { Gene expression for CSPG synthesis and degradation } \\
\text { pathways is altered in mice sleep deprived following fear } \\
\text { conditioning }\end{array}$ \\
\hline $\begin{array}{l}\text { Harkness et al., } \\
2020\end{array}$ & $\begin{array}{l}\text { Diurnal rhythms of PNN intensity and OTX2 expression } \\
\text { occurs in the rat medial prefrontal cortex, with decreased } \\
\text { PNN intensity and OTX2 expression during sleep. }\end{array}$ \\
\hline Nguyen et al., 2020 & $\begin{array}{l}\text { IL-33 signaling stimulates ECM engulfment by microglia, } \\
\text { promoting experience-dependent synaptic plasticity }\end{array}$ \\
\hline $\begin{array}{l}\text { Pantazopoulos } \\
\text { et al., } 2020 a\end{array}$ & $\begin{array}{l}\text { PNN composition decreases during sleep and increases } \\
\text { during wakefulness; sleep deprivation prevents decreases } \\
\text { in PNN composition }\end{array}$ \\
\hline $\begin{array}{l}\text { Pantazopoulos } \\
\text { et al., 2020a }\end{array}$ & $\begin{array}{l}\text { The CSPG protease cathepsin-S is expressed in a diurnal } \\
\text { manner by microglia in the mouse brain, antiphase to PNN } \\
\text { composition rhythms. }\end{array}$ \\
\hline
\end{tabular}

of plasticity and mark the closure of these periods by conferring an adult form of restricted plasticity (Pizzorusso et al., 2002; Gogolla et al., 2009).

Perineuronal nets have been historically considered as very stable structures, and the holes in PNNs are hypothesized as storage sites for long term memories (Tsien, 2013). However, if PNNs are such highly stable structures that restrict plasticity, how are new memories formed, and how are they strengthened during sleep? PNNs would need to be modified to weaken their restrictive properties during sleep in order for synaptic downscaling and/or synaptic reorganization to occur for memory consolidation. Several studies suggest that endogenous proteases modify PNNs during learning to allow for formation of synapses (Nagy et al., 2007; Brown et al., 2009; Ganguly et al., 2013; Banerjee et al., 2017; Slaker et al., 2018). A number of endogenous proteases expressed in the adult brain can cleave chondroitin sulfate proteoglycans (CSPGs), key components of PNNs. Endogenous proteolytic remodeling of ECM components, including CSPGs, is mediated by several proteases including matrix metalloproteases (MMPs), 'a disintegrin and metalloproteases' (ADAMs) and 'a disintegrin and metalloproteases with a thrombospondin motif (ADAMTS) (Muir et al., 2002; Medina-Flores et al., 2004; Hobohm et al., 2005; Porter et al., 2005; Bajor and Kaczmarek, 2013). Several of these proteases, such as MMP-9, modify ECM composition during learning tasks, possibly allowing for formation of new synapses in response to environmental stimuli (Nagy et al., 2007; Brown et al., 2009; Ganguly et al., 2013). For example, MMP-9 expression is induced in the amygdala, prefrontal cortex, and hippocampus during contextual fear learning (Ganguly et al., 2013). Pharmacological disruption of MMP activity results in disruption of reconsolidation of fear memory, suggesting that MMP expression is a necessary component for this process (Brown et al., 2009). Similar disruption of MMP-3 and MMP-9 activity in the hippocampus results in impairment of spatial memory (Wright et al., 2007) and avoidance learning (Nagy et al., 2007).

These effects may be through regulation of synaptic stabilization. For example, increased MMP9 expression has been shown to coincide with dendritic spine remodeling (Szklarczyk et al., 2002), and MMP9 is required for late-stage LTP and hippocampal dependent memory (Nagy et al., 2006). In vivo and in vitro studies suggest that PNNs stabilize synaptic strength. An increasing number of studies suggest that CSPGs and PNNs are critically involved in the regulation of synaptic plasticity. For example, electrophysiological recordings from in vitro mouse hippocampal slices treated with chondroitinase $\mathrm{ABC}$ to remove CSPGs, show a two-fold decrease in long-term potentiation (LTP) but not in short-term plasticity (Bukalo et al., 2001). A similar decrease of LTP was observed in mice lacking a key PNN component, tenascin-R, suggesting that CSPG regulation of long-term synaptic plasticity occurs through modulation of PNN composition (Bukalo et al., 2001). The strength of hippocampal LTP has been shown to vary in a circadian manner (Chaudhury et al., 2005), and PNNs regulate synaptic strength and stability (Bukalo et al., 2001; Brakebusch et al., 2002; Geissler et al., 2013) suggesting that PNN composition may be regulated in a circadian manner, potentially through proteases.

We recently reported circadian rhythms in PNN composition in the mouse brain, with lower densities of wisteria floribunda agglutinin (WFA) labeled PNNs during sleep and higher densities during wakefulness (Pantazopoulos et al., 2020a). PNNs labeled by chondroitin sulfate synthase 1 antibodies display rhythms in densities of CHSY-immunoreactive PNNs in the hippocampus that mirror WFA labeled PNN densities in the same animals (Figures 2, 3), suggesting that some components of PNNs are produced in a circadian manner. Furthermore, $5 \mathrm{~h}$ of sleep deprivation prevented decreases in PNN densities (Pantazopoulos et al., 2020a). Recent work shows similar increases in PNN composition in the prelimbic cortex of sleep deprived rats and provides further support that PNN composition is decreased during sleep (Harkness et al., 2019). Our PNN labeling and quantification method represents the number of WFA labeled PNNs above a certain detection threshold as weakly labeled PNNs do not meet detection criteria. We interpret our results as altered PNN composition rather than 

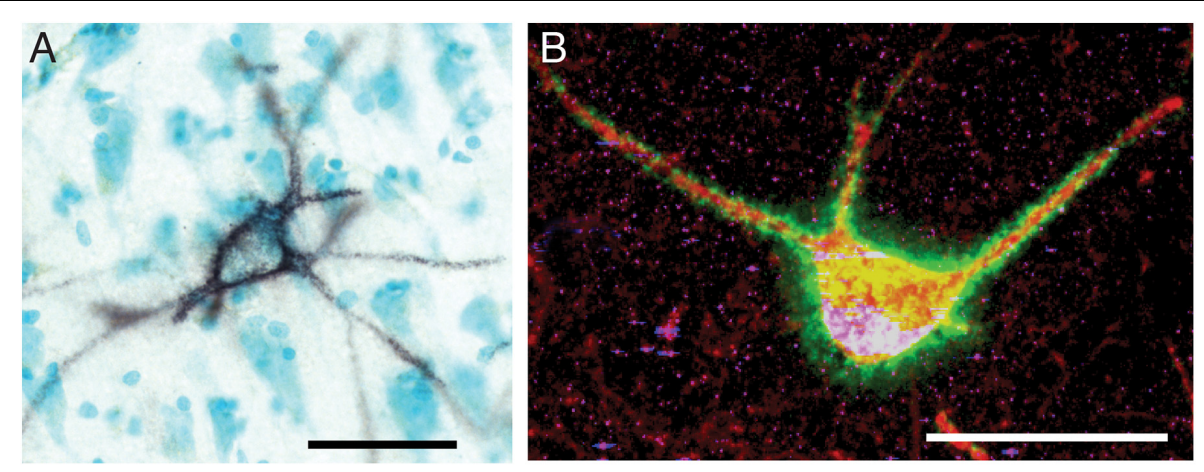

FIGURE 1 | Perineuronal nets in the human and mouse hippocampus. (A) Photomicrograph of a representative perineuronal net labeled by wisteria floribunda agglutinin in the human hippocampus. Cells are counterstained with methyl green according to previously published methods (Pantazopoulos et al., 2010b). (B) Confocal image of a perineuronal net in the mouse hippocampus labeled with wisteria floribunda agglutinin (green), surrounding a parvalbumin positive neuron (red) co-expressing synapsin-1 (blue). Scale bars $=50 \mu \mathrm{m}$.

fluctuating numbers of PNNs. Similar diurnal rhythms in PNN composition were reported recently in the rat medial prefrontal cortex (Harkness et al., 2020). Decreased PNN composition during sleep (Pantazopoulos et al., 2020a) coincides with reduced LTP amplitude during the light phase in the hippocampus (Chaudhury et al., 2005). Further evidence for the involvement of ECM molecules including CSPGs in memory consolidation during sleep comes from a recent single cell gene expression profiling study describing altered gene expression of CSPG synthesis and degradation pathways in CamKII $\alpha$ neurons when animals that slept normally were compared to sleep deprived animals following fear conditioning (Delorme J. et al., 2020).

Perineuronal nets may contribute to synaptic regulation in several aspects (Figure 4). For example, PNNs may be involved in circadian regulation of synaptic strength through their regulation of glutamatergic receptors. ECMs regulate glutamate receptor trafficking (Frischknecht et al., 2009; Frischknecht and Gundelfinger, 2012). Long-term (72 h) of sleep deprivation has been shown to result in decreased long-term potentiation (LTP), a form of synaptic plasticity that is associated with memory consolidation (Martin et al., 2000) in CA1 hippocampal neurons. Furthermore, short term ( $5 \mathrm{~h}$ ) of sleep deprivation has also been shown to disrupt LTP (Vecsey et al., 2009; Havekes et al., 2016). Reduction in LTP was associated with reduced NMDA receptor activity and surface expression of the NR1 and NR2A subunits of the NMDA receptor in sleep deprived rats, indicating that sleep deprivation prevents translocation of NMDA receptors to the cell surface (McDermott et al., 2006). Reduction in LTP associated with trafficking of NMDA receptors to the surface of CA1 neurons has also been shown following $24 \mathrm{~h}$ of sleep deprivation (Chen et al., 2006). Day/night differences in the AMPA/NMDA ratio were reported recently in the rat medial prefrontal cortex, with increased AMPA/NMDA ratio during the night (ZT18) compared to the day (ZT6). This was accompanied by increased vGlut1 glutamatergic synapses on PVB neurons at ZT18 and increased PNN intensity (Harkness et al., 2020).

Circadian rhythms of PNN composition (Harkness et al., 2020; Pantazopoulos et al., 2020a) may also contribute to memory consolidation through the regulation of PVB neuron firing properties. GABAergic inhibition of excitatory neurons is proposed to contribute to synaptic downscaling by promoting long term depression (LTD) (Niethard et al., 2016), in agreement with reported decreased LTP amplitude during the light phase (Chaudhury et al., 2005). PVB neuron firing rates increase during sleep, particularly during REM sleep, accompanied by overall reduction in pyramidal neuron activity (Niethard et al., 2016). Removal of PNNs through chondroitinase ABC treatment has been shown to enhance frequency of spontaneous inhibitory postsynaptic currents on hippocampal pyramidal neurons, which contributes to impairment of LTP and fear memory consolidation (Shi et al., 2019), suggesting PNN degradation enhanced PVB neuron inhibition of pyramidal cells. However, PVB neuron activity is also essential for memory consolidation (Ognjanovski et al., 2017; Xia et al., 2017), suggesting a more complex role of PNN regulation of PVB neuron activity in physiological conditions, possibly reflected by more subtle changes in PNN composition by endogenous proteases rather than broad PNN degradation caused by chABC administration. Diurnal and circadian fluctuations in excitatory/inhibitory balance have also been reported in rodents and humans (Chellappa et al., 2016; Bridi et al., 2020). Circadian rhythms in PNN composition may contribute to daily rhythms in excitatory/inhibitory balance through regulation of PVB neuron firing as well as regulation of excitatory and inhibitory synapses on PVB soma (Carceller et al., 2020; Harkness et al., 2020). Taken together, these data suggest that PNN composition changes during sleep may in part contribute to synaptic downscaling by allowing increased inhibitory inhibition for synapse depotentiation by PVB neurons.

Several factors may contribute to circadian regulation of PNN composition (Figure 4). Sleep deprivation has been shown to decrease both mRNA expression and enzymatic activity of MMP9 (Taishi et al., 2001), suggesting that increased MMP9 activity during sleep may contribute to PNN composition changes. MMPs, including MMP-9, are primarily produced by 
A

CA1

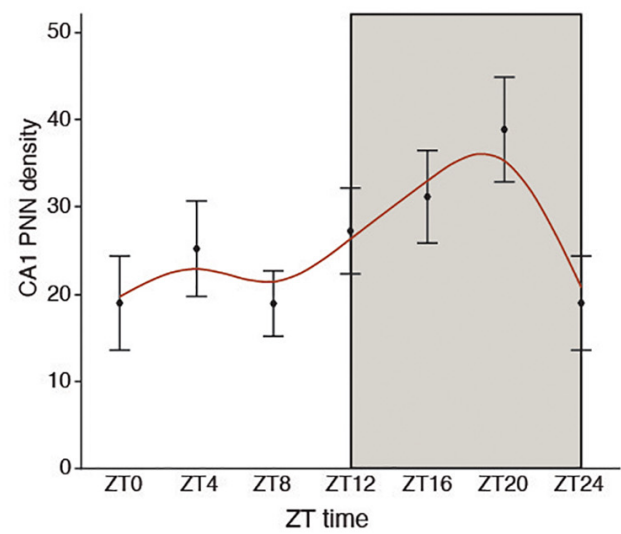

C

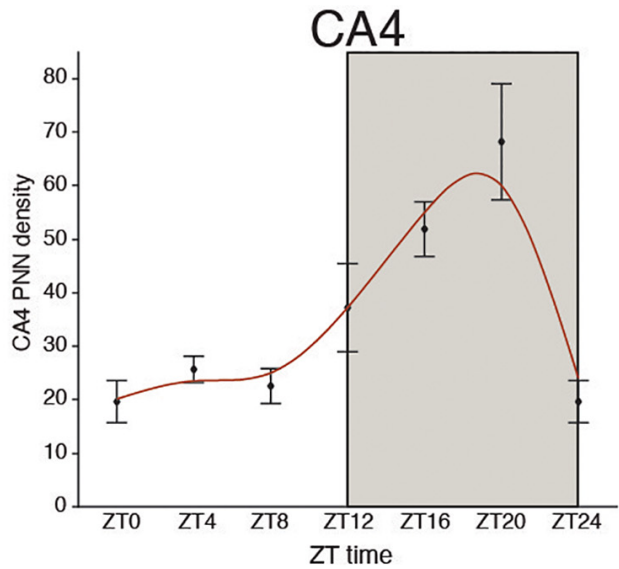

E

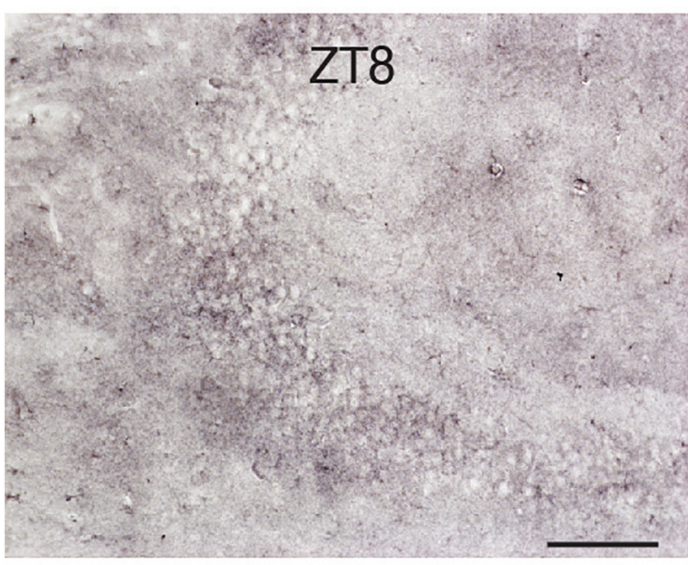

B

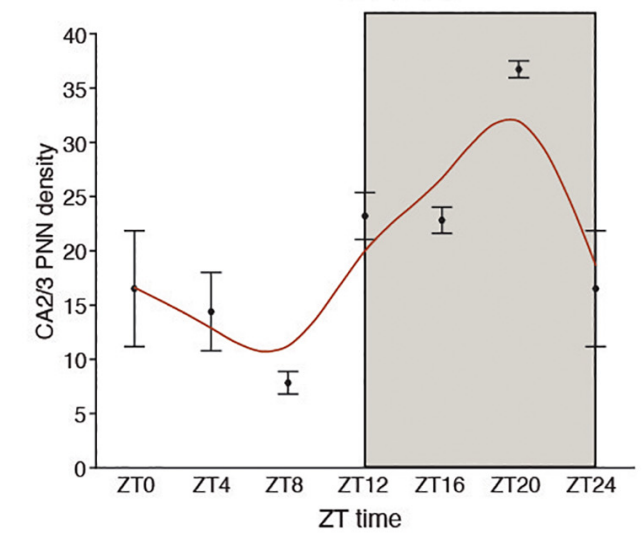

D

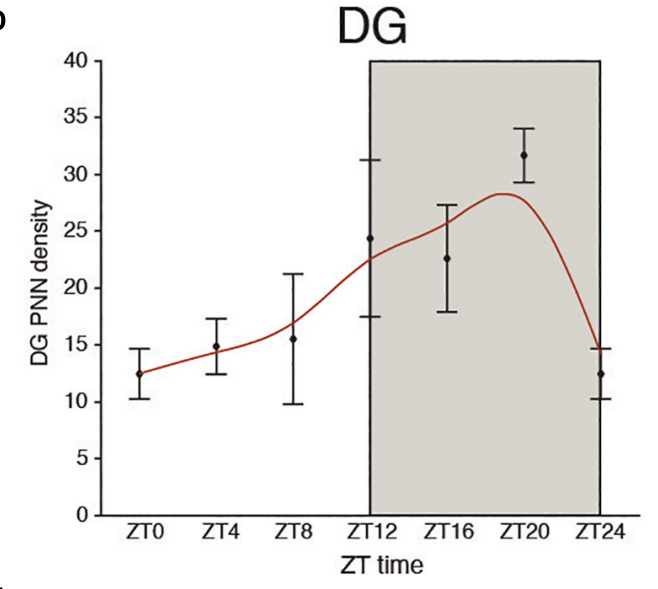

F

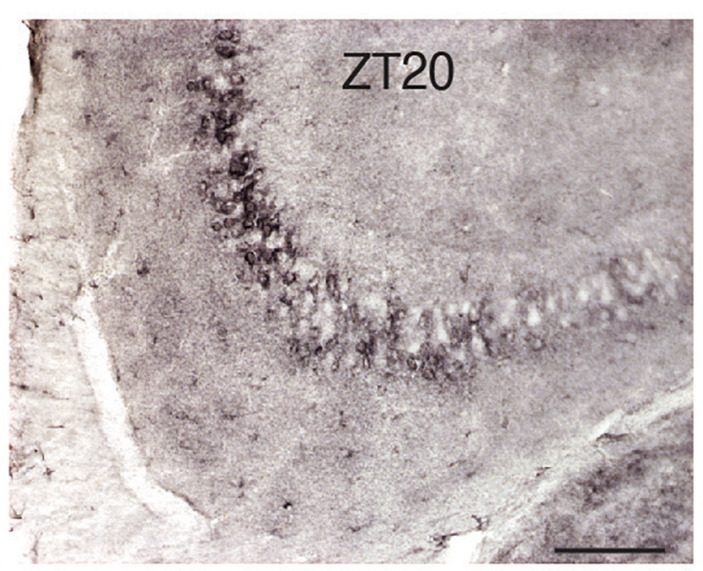

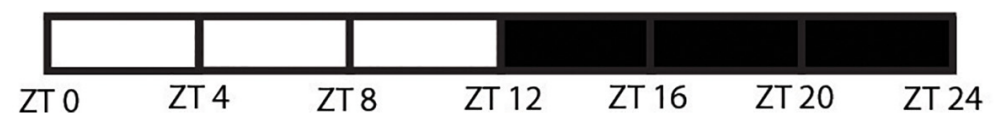

FIGURE 2 | Diurnal rhythms of chondroitin sulfate synthase 1 labeled perineuronal nets in the mouse hippocampus. CHSY1 immunoreactive PNNs were labeled with rabbit anti-CHSY1antibody (cat\#14420-1-AP, ProteinTech) at 1:500 $\mu$ l dilution. Immunolabeling and quantification was conducted on serial sections from the same mice in our previous study according to the same methods described in detail (Pantazopoulos et al., 2020a). Diurnal rhythms of chondroitin sulfate synthase 1 (CHSY1) immunoreactive PNNs were observed in hippocampal sector CA1 (A) CA2/3 (B), CA4 (C) and the dentate gyrus (D), with peaks at ZT20 and troughs at ZT8. Error bars represent standard deviation. Representative low magnification images of CHSY1 labeling in the mouse hippocampus at ZT 8 (E) and ZT 20 (F). 


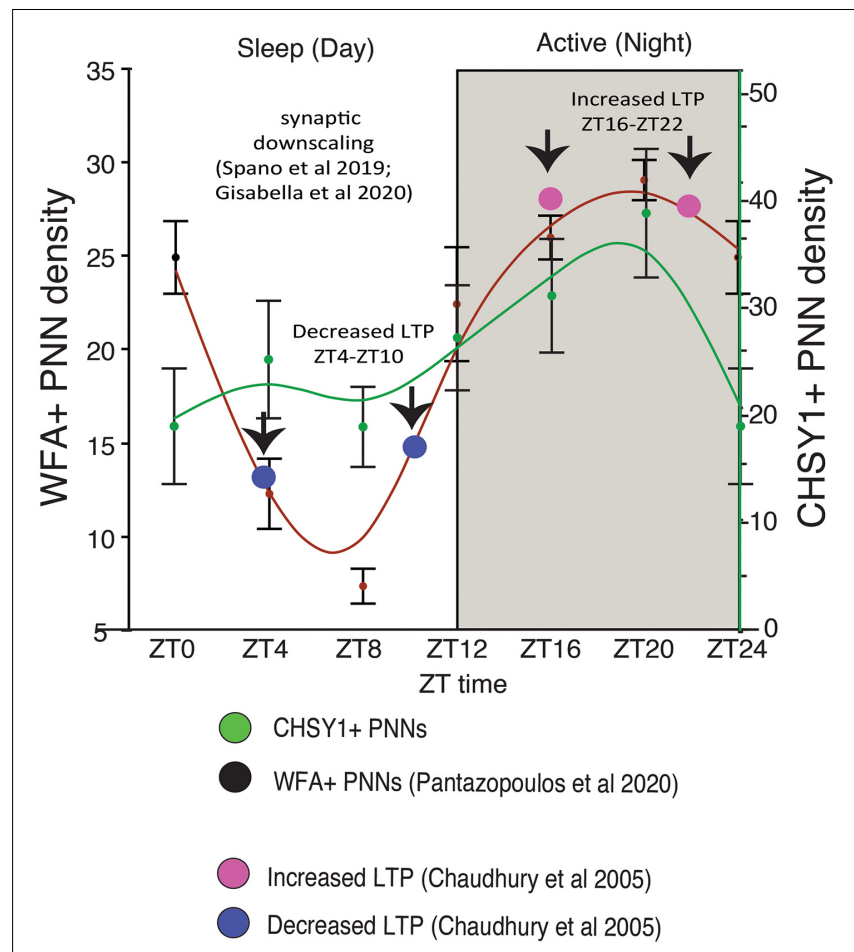

FIGURE 3 | Diurnal PNN Rhythms Coincide with Rhythms in CHSY1 Expression and Memory Consolidation Processes. Diurnal rhythms in the numerical density of WFA+ PNNs decreases during the day as mice sleep, reaching the lowest density in WFA+ PNN numbers between ZT 4-ZT 10 (red curved line). This coincides with decreased expression of CHSY1 PNNs (green curved line) and the reported daytime decrease in LTP [blue circles, (Chaudhury et al., 2005)]. This decrease in PNNs also coincides with reported broad synaptic downscaling in this region (Spano et al., 2019; Gisabella et al., 2020). In comparison, the numerical density of WFA+ and CHSY1 immunoreactive PNNs peaks during the dark at $\sim Z T 20$ during the active period for nocturnal mice, coinciding with the reported increase in LTP at night in mice [pink circles, (Chaudhury et al., 2005)]. These results suggest that decreases in PNN composition during sleep coinciding with synaptic downscaling and decreased LTP, potentially allowing for memory consolidation. PNN composition is restored during the active wake periods, in part through $\mathrm{CHSY} 1$ expression.

astrocytes and microglia in the brain (Rosenberg et al., 2001; Cahoy et al., 2008). Recent studies point to the involvement of microglia in degrading ECM components during sleep. A large number of recent studies have established the role of microglia in the regulation of synaptic plasticity in the adult brain (Tremblay et al., 2010; Paolicelli et al., 2011; Schafer et al., 2012, 2014; Miyamoto et al., 2013; Wake et al., 2013; Kim et al., 2017; Bolós et al., 2018; Stevens and Schafer, 2018). For example, microglia continuously sense synapses in areas of high synaptic activity, monitoring the synaptic environment and prune synapses (Tremblay et al., 2010; Paolicelli et al., 2011; Schafer et al., 2012, 2014; Miyamoto et al., 2013; Wake et al., 2013; Kim et al., 2017; Stevens and Schafer, 2018). Microglial dysfunction in the adult hippocampus has been shown to result in a reduction of dendritic spines along with increased ECM expression (Bolós et al., 2018), suggesting microglia participate in degrading the ECM to allow for increased synaptic plasticity. This process may be under control of the molecular circadian clock, as suggested by studies describing that the circadian molecular clock in microglia regulates several processes including microglial morphology, immune response, and synaptic processing (Hayashi et al., 2013a,b; Fonken et al., 2015).

Cathepsin-S may represent one of the components through which microglia regulate PNN composition in a circadian manner. Cathepsin-S is a protease produced by microglia reported to cleave several CSPGs (Petanceska et al., 1996; Pantazopoulos et al., 2020a). Cathepsin-S knockout mice, in which diurnal rhythms of dendritic spine density were reported (Hayashi et al., 2013a), also display deficits in novel object recognition (Takayama et al., 2017), supporting the hypothesis that cathepsin-S rhythms regulate key roles of PNNs in memory processing. Our evidence for circadian rhythms of cathepsin-S expression in microglia in the mouse brain, antiphase to PNN rhythms, and evidence that cathepsin-S reduces PNN labeling, suggests that increased expression of cathepsin-S proteases from microglia during sleep are involved in weakening PNN composition (Pantazopoulos et al., 2020a), potentially allowing for synaptic remodeling during memory consolidation. Recent evidence that microglia promote synaptic plasticity by degrading ECM molecules including the key PNN components aggrecan and brevican through cathepsinC and other proteases (Nguyen et al., 2020) provides further support that microglia are involved in mediating changes in PNN composition during sleep to allow for memory consolidation processes.

Several studies point to multiple pathways in which neurons and microglia may modify PNN composition (Bertocchi et al., 2020; Harkness et al., 2020; Nguyen et al., 2020; Pantazopoulos et al., 2020a). Neurons signal to microglia through IL-33 to promote experience dependent synaptic plasticity in part by stimulating engulfment of ECMs (Nguyen et al., 2020). This process is impaired in IL-33 deficient mice, resulting in impaired spatial memory precision (Nguyen et al., 2020). Neuropeptide-Y (NPY) signaling is also involved in regulating hippocampal PNN composition to allow for plasticity during spatial learning (Bertocchi et al., 2020). Conditional loss of NPY receptors leads to increased PNN intensity in the hippocampus, associated with impaired spatial learning, and enzymatic digestion of PNNs restores learning abilities (Bertocchi et al., 2020). In the rat medial prefrontal cortex, increases in PNN intensity during the night were accompanied by increased OTX2 expression in PVB cells with and without PNNs (Harkness et al., 2020). OTX2 has been shown to target PVB cells through binding of a 15 amino acid peptide sequence within OTX2 to di-sulfated chondroitin sulfate (CSD and CS-E) in PNNs (Beurdeley et al., 2012). Blocking this peptide sequence reduces PNN and PVB expression and enhances synaptic plasticity (Beurdeley et al., 2012), suggesting that OTX2 may contribute to the circadian regulation of PNN composition. Furthermore, studies in xenopus suggest that OTX2 influences CLOCK expression in a positive, bidirectional manner (Green et al., 2001; Morgan, 2002). Together these 


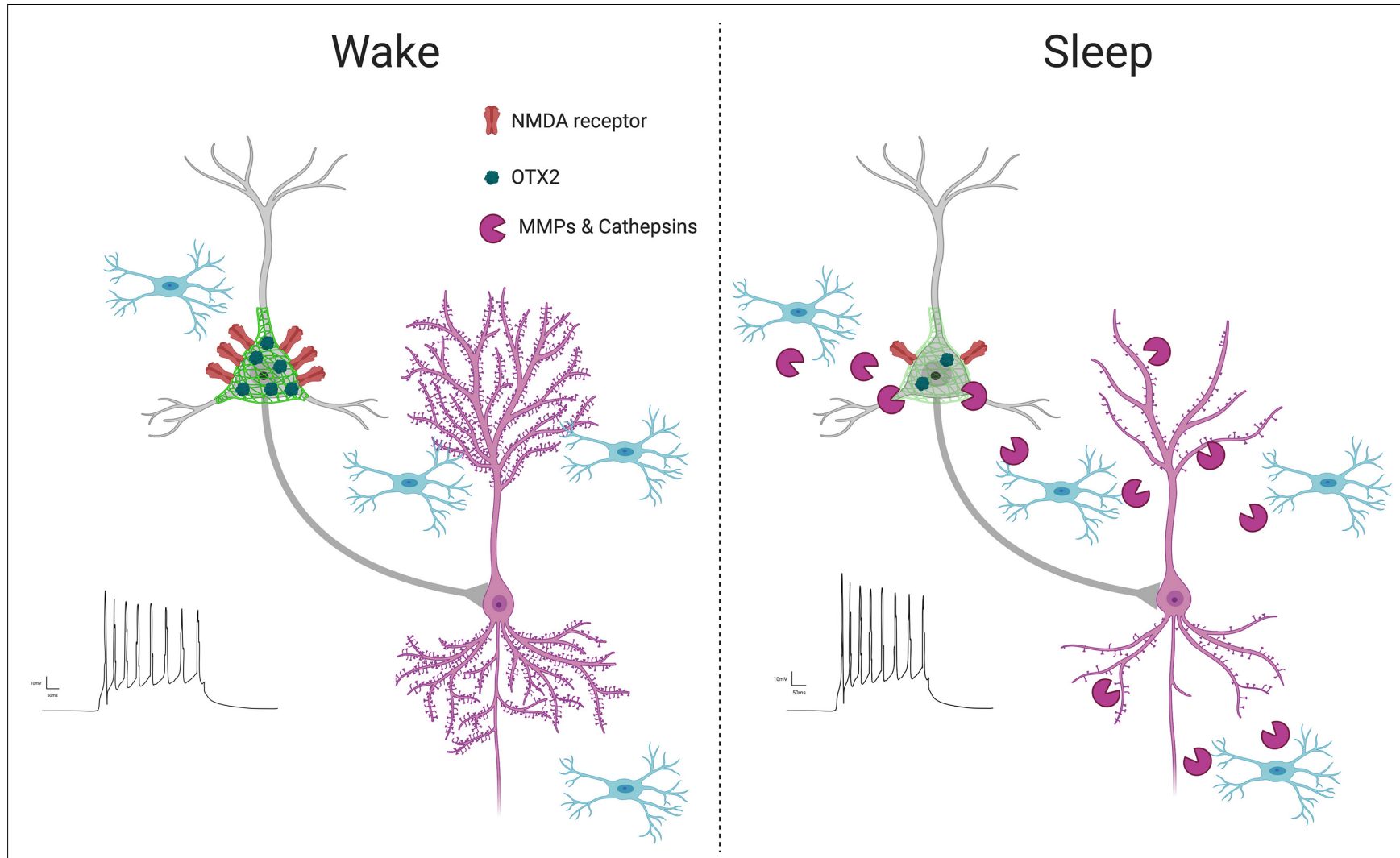

FIGURE 4 | PNN intensity during wakefulness vs. sleep. PNNs display increased intensity during wakefulness (Harkness et al., 2020; Pantazopoulos et al., 2020a), coinciding with increased glutamatergic receptor activity (Harkness et al., 2020) and OTX2 expression (Harkness et al., 2020). This condition promotes LTP as new synapses are formed when interacting with the environment in active states, reflected by increased LTP (Chaudhury et al., 2005) and dendritic spine numbers on pyramidal neurons (Spano et al., 2019; Gisabella et al., 2020). In contrast, PNN intensity decreases during sleep, coinciding with several factors involved in synaptic regulation, including increased expression of proteases in part by microglia (Taishi et al., 2001; Pantazopoulos et al., 2020a), decreased OTX2 protein and glutamatergic receptor activity (Harkness et al., 2020), increased PVB neuron firing (Niethard et al., 2016), decreased LTP (Chaudhury et al., 2005) and decreased dendritic spines on pyramidal neurons, as memories are consolidated during synaptic downscaling (Spano et al., 2019; Gisabella et al., 2020).

studies suggest OTX2-CLOCK interactions may contribute to circadian PNN composition rhythms and in turn synaptic reorganization during sleep.

In addition to PNNs, CSPGs are also located on perisynaptic regions and several ECM structures that may regulate synaptic plasticity. For example, perisynaptic aggregates of the CSPGs aggrecan and brevican have been reported around neurons devoid of PNNs (Lendvai et al., 2012, 2013). Brevican is enriched in synaptic membrane protein fractions (Seidenbecher et al., 1995) and is essential for hippocampal synapse maturation (Favuzzi et al., 2017). Brevican has been shown to be critically involved in the regulation of synaptic plasticity (Yuan et al., 2002; Blosa et al., 2015; Sonntag et al., 2018; Gottschling et al., 2019; Mitlohner et al., 2020) and cleavage of BCAN by ADAMTS4 increases in the rodent hippocampus following excitotoxic lesion, coinciding with reduced synaptic density (Yuan et al., 2002). CSPG structures formed by clusters of chondroin- 6 sulfate have also been described in several species (Hayashi et al., 2007; HoriiHayashi et al., 2010; Pantazopoulos et al., 2015), and are proposed to contribute to the regulation of synaptic plasticity (Hayashi et al., 2007; Horii-Hayashi et al., 2010; Chelini et al., 2018).
Alterations in circadian rhythms of endogenous ECM proteases and ECM molecules thus may impact memory consolidation processes in several manners, including through ECM regulation of dendritic spines in excitatory neurons.

\section{MEMORY CONSOLIDATION AND EXTRACELLULAR MATRIX MOLECULES IN PSYCHIATRIC DISORDERS}

Disturbances in sleep and circadian rhythms, along with memory dysfunction are two key features shared across many psychiatric disorders, including schizophrenia (SZ), major depression disorder (MDD), bipolar disorder (BD), post-traumatic stress disorder (PTSD) and Alzheimer's Disease (Bliwise, 1993; Hofman et al., 1996; Leibenluft et al., 1996; Colombo et al., 1999; Lin et al., 2000; Van Cauter et al., 2000; Huang et al., 2002; Mellman et al., 2002; Jackson et al., 2003; Harvey et al., 2005; Armitage, 2007; Benedetti et al., 2007; Ferrarelli et al., 2007; Wang and Teichtahl, 2007; Manoach et al., 2010, 2014, 2016; McCarthy et al., 2012, 2013, 2016, 2019; Bunney and Bunney, 2013; Burton 
et al., 2013; Li et al., 2013; McClung, 2013; Palagini et al., 2013; Parsons and Ressler, 2013; Colrain et al., 2014; Medina et al., 2014; Narishige et al., 2014; Bunney et al., 2015; Wang et al., 2015; Chen et al., 2016; Pagani et al., 2016; Pantazopoulos et al., 2017; Nudell et al., 2019; Koob and Colrain, 2020). Furthermore, alterations in ECMs (Table 2) and synaptic markers have also been reported across these disorders (DeKosky and Scheff, 1990; Terry et al., 1991; Scheff and Price, 1993; Woo et al., 2004; Dorph-Petersen et al., 2009; Feyissa et al., 2009; Sweet et al., 2009; Kristiansen et al., 2010; Schmitt et al., 2010; Vrajova et al., 2010; Penzes et al., 2011; Duman and Aghajanian, 2012; Kang et al., 2012; Duric et al., 2013; Glausier and Lewis, 2013; Licznerski and Duman, 2013; Konopaske et al., 2014, 2015; Shelton et al., 2015; MacDonald et al., 2017).

\section{Schizophrenia}

Synaptic deficits and sleep dysfunction are both widely reported in SZ. Decreased dendritic spines on pyramidal neurons are an established feature of SZ and have been reported in several brain regions, including the dorsolateral prefrontal cortex, visual cortex, and striatum (Roberts et al., 1996; Garey et al., 1998; Glantz and Lewis, 2000; Konopaske et al., 2014; Parker and Sweet, 2017; McKinney et al., 2019). A recent meta-analysis of human postmortem studies provides additional support for reduced synapses in cortical regions in SZ (Berdenis van Berlekom et al., 2020). Deficits in molecular synaptic markers, particularly for NMDA receptors, have also been reported in several brain regions in SZ (Woo et al., 2004; Kristiansen et al., 2010; Schmitt et al., 2010; Vrajova et al., 2010). Sleep and circadian rhythm disturbances may contribute to synaptic deficits in SZ. Sleep deprivation has been shown to result in decreased longterm plasticity (LTP) in CA1 hippocampal neurons, associated with reduced NMDA receptor activity and a reduced surface expression of the NR1 and NR2A subunits of the NMDA receptor in sleep deprived rats, indicating that sleep deprivation prevents translocation of NMDA receptors to the cell surface (McDermott et al., 2006).

Recent studies point to sleep and circadian rhythm disturbances as key aspects of schizophrenia (SZ) (Ferrarelli et al., 2007; Manoach et al., 2014, 2016; Ferrarelli, 2015, 2020; Ferrarelli and Tononi, 2017; D’Agostino et al., 2018; Baran et al., 2019; Manoach and Stickgold, 2019; Merikanto et al., 2019; Seney et al., 2019; Delorme T.C. et al., 2020; Gerstenberg et al., 2020; Markovic et al., 2020; Meyer et al., 2020). Furthermore, altered diurnal molecular expression rhythms have been recently reported in the prefrontal cortex of subjects with SZ using RNAseq profiling of postmortem brain samples, suggesting broad molecular circadian rhythm disturbances in this disease (Seney et al., 2019). Disrupted sleep and circadian rhythms may impair synaptic downscaling of unnecessary spines during sleep (Tononi and Cirelli, 2006, 2014), and strengthening of selective spines for enhancement of specific memories (Rasch and Born, 2013; Yang et al., 2014; Dudai et al., 2015). Despite the clinical and genetic heterogeneity of SZ (Fanous et al., 2012; Cross-Disorder Group of the Psychiatric Genomics Consortium et al., 2013), sleep dysfunction, specifically decreased sleep spindles and memory consolidation deficits, is emerging as a consistent characteristic of the disease (Ferrarelli et al., 2007; Manoach et al., 2014, 2016; Ferrarelli, 2015, 2020; Ferrarelli and Tononi, 2017; D’Agostino et al., 2018; Baran et al., 2019; Manoach and Stickgold, 2019; Merikanto et al., 2019; Gerstenberg et al., 2020; Markovic et al., 2020). Decreases in sleep spindles are found together with memory consolidation deficits in patients with SZ (Ferrarelli et al., 2007; Manoach et al., 2010, 2014). Sleep spindle deficits have been reported in several independent studies (Ferrarelli et al., 2007; Manoach et al., 2014, 2016; Ferrarelli, 2015, 2020; Ferrarelli and Tononi, 2017; D’Agostino et al., 2018; Baran et al., 2019; Manoach and Stickgold, 2019; Merikanto et al., 2019; Gerstenberg et al., 2020; Markovic et al., 2020) including in unmedicated patients with SZ, and in first-degree relatives, suggesting that this represents a core genetic component of the disease rather than medication effects or a degenerative consequence of disease progression. Sleep spindle deficits are highly associated with psychosis, and disease prognosis (Manoach et al., 2016; Gerstenberg et al., 2020; Markovic et al., 2020).

Circadian rhythms in PNN composition may impact regulation of sleep spindles and memory consolidation in SZ in several ways. Our group and others have reported PNN deficits in several brain regions in SZ (Pantazopoulos et al., 2010b, 2014, 2015; Mauney et al., 2013; Enwright et al., 2016; Steullet et al., 2017). Furthermore, we recently reported broad alterations of ECM molecule gene expression in subjects with SZ associated with cognitive deficits, impacting CSPG core proteins, chondroitin sulfate synthesis pathways, and endogenous proteases across several cortical and subcortical brain regions (Pantazopoulos et al., 2020b). Recent evidence for altered diurnal molecular expression rhythms of subjects with SZ (Seney et al., 2019) suggests broad molecular circadian rhythm disturbances, which may impact several of these memory consolidation processes in which ECM molecules are involved. Broad ECM abnormalities, and potentially disrupted expression rhythms in ECM molecules in SZ, may impact PNNs and other CSPGs that regulate synaptic function and NMDA receptor trafficking, and may thus contribute to memory consolidation deficits through disruption of synaptic regulation proposed to occur during sleep (Tononi and Cirelli, 2006; Rasch and Born, 2013; Tononi and Cirelli, 2014; Puentes-Mestril and Aton, 2017; Havekes and Aton, 2020). In turn, these memory consolidation processes may contribute to synaptic deficits in SZ (Penzes et al., 2011; Glausier and Lewis, 2013; Shelton et al., 2015; MacDonald et al., 2017).

Circadian rhythms in PNN composition may also impact sleep spindles in SZ. PNN PNNs regulate firing rates of neurons expressing parvalbumin (PVB), including those in the thalamic reticular nucleus (TRN) that generate sleep spindles (Csillik et al., 2005; Katsuki et al., 2017; Latchoumane et al., 2017; Fernandez et al., 2018; Thankachan et al., 2019). Decreases of PNNs and PVB neurons were detected in the TRN of subjects with schizophrenia (Steullet et al., 2017). Potentially disrupted PNN rhythms in this region may impair the ability of the TRN to generate sleep spindles, impacting memory consolidation processes. 
TABLE 2 | Evidence for ECM molecules and PNNs in psychiatric disorders.

\begin{tabular}{|c|c|c|}
\hline Reference & $\begin{array}{l}\text { Psychiatric Disorder of } \\
\text { Interest }\end{array}$ & Summary of Findings \\
\hline $\begin{array}{l}\text { Morawski et al., } \\
\text { 2004; Morawski } \\
\text { et al., } 2010\end{array}$ & Alzheimer's Disease (AD) & PNNs protect neurons in Alzheimer's Disease patients \\
\hline Baig et al., 2005 & Alzheimer's Disease (AD) & WFA labeled perineuronal nets are decreased in the frontal cortex of patients with AD \\
\hline Nagy et al., 2006 & $\begin{array}{l}\text { Post-Traumatic Stress } \\
\text { Disorder (PTSD) }\end{array}$ & MMP9 KO mice display fear memory and LTP deficits \\
\hline Wright et al., 2007 & $\begin{array}{l}\text { Substance Use Disorders } \\
\text { (SUD) }\end{array}$ & Ethanol impairs spatial memory and reduces MMP-9 levels. \\
\hline Brown et al., 2007 & $\begin{array}{l}\text { Substance Use Disorders } \\
\text { (SUD) }\end{array}$ & $\begin{array}{l}\text { Broad-spectrum MMP inhibition disrupts both acquisition and consolidation of cocaine reward } \\
\text { memory in rodents }\end{array}$ \\
\hline $\begin{array}{l}\text { Mizoguchi et al., } \\
2007\end{array}$ & $\begin{array}{l}\text { Substance Use Disorders } \\
\text { (SUD) }\end{array}$ & $\begin{array}{l}\text { MMP-9 inhibition reduces methamphetamine induced conditioned place preference and nucleus } \\
\text { accumbens dopamine levels }\end{array}$ \\
\hline Brown et al., 2009 & $\begin{array}{l}\text { Post-Traumatic Stress } \\
\text { Disorder (PTSD) }\end{array}$ & $\begin{array}{l}\text { Intracerebroventricular administration of the MMP inhibitor FN-439 disrupts fear memory } \\
\text { reconsolidation in rodents }\end{array}$ \\
\hline $\begin{array}{l}\text { Samochowiec } \\
\text { et al., } 2010\end{array}$ & $\begin{array}{l}\text { Substance Use Disorders } \\
\text { (SUD) }\end{array}$ & MMP-9 polymorphism is associated with alcoholism \\
\hline $\begin{array}{l}\text { Pantazopoulos } \\
\text { et al., 2010b }\end{array}$ & $\begin{array}{l}\text { Bipolar Disorder (BD) and } \\
\text { Schizophrenia (SZ) }\end{array}$ & WFA labeled PNNs are decreased in the amygdala and entorhinal cortex of subjects with SZ \\
\hline Mauney et al., 2013 & $\begin{array}{l}\text { Bipolar Disorder (BD) and } \\
\text { Schizophrenia (SZ) }\end{array}$ & WFA labeled PNNs are decreased in the prefrontal cortex of subjects with SZ \\
\hline $\begin{array}{l}\text { Pantazopoulos } \\
\text { et al., } 2014\end{array}$ & $\begin{array}{l}\text { Bipolar Disorder (BD) and } \\
\text { Schizophrenia (SZ) }\end{array}$ & WFA labeled PNNs are decreased in the hippocampus of subjects with SZ \\
\hline $\begin{array}{l}\text { Pantazopoulos } \\
\text { et al., } 2015\end{array}$ & $\begin{array}{l}\text { Bipolar Disorder (BD) and } \\
\text { Schizophrenia (SZ) }\end{array}$ & $\begin{array}{l}\text { Aggrecan labeled PNNs are decreased in the amygdala of subjects with SZ, and CS-6 labeled } \\
\text { PNNs are decreased in the amygdala of subjects with SZ and BD }\end{array}$ \\
\hline $\begin{array}{l}\text { Enwright et al., } \\
2016\end{array}$ & $\begin{array}{l}\text { Bipolar Disorder (BD) and } \\
\text { Schizophrenia (SZ) }\end{array}$ & Intensity of WFA labeling is reduced in the dorsolateral prefrontal cortex of subjects with SZ \\
\hline Steullet et al., 2017 & $\begin{array}{l}\text { Bipolar Disorder (BD) and } \\
\text { Schizophrenia (SZ) }\end{array}$ & $\begin{array}{l}\text { WFA labeled PNNs are reduced in the thalamic reticular nucleus in subjects with SZ and in subjects } \\
\text { with BD }\end{array}$ \\
\hline Smith et al., 2011 & $\begin{array}{l}\text { Substance Use Disorders } \\
\text { (SUD) }\end{array}$ & MMP inhibition reduced escalated ethanol self-administration in rodents \\
\hline $\begin{array}{l}\text { Shah and Lodge, } \\
2013\end{array}$ & $\begin{array}{l}\text { Substance Use Disorders } \\
\text { (SUD) }\end{array}$ & $\begin{array}{l}\text { PNN degradation in the ventral hippocampus enhances dopamine VTA activity and amphetamine } \\
\text { response }\end{array}$ \\
\hline Kovatsi et al., 2013 & $\begin{array}{l}\text { Substance Use Disorders } \\
\text { (SUD) }\end{array}$ & $\begin{array}{l}\text { Subjects with chronic heroin use have altered blood serum levels of MMP-9, MMP-2, TIMP-1 and } \\
\text { TIMP-2 }\end{array}$ \\
\hline $\begin{array}{l}\text { Natarajan et al., } \\
2013\end{array}$ & $\begin{array}{l}\text { Substance Use Disorders } \\
\text { (SUD) }\end{array}$ & $\begin{array}{l}\text { Nicotine induces transient changes in MMP-2, } 3 \text { and } 9 \text { in the rodent hippocampus, and MMP } \\
\text { inhibition impairs nicotine conditioned place preference }\end{array}$ \\
\hline Guirado et al., 2014 & $\begin{array}{l}\text { Major Depression Disorder } \\
\text { (MDD) }\end{array}$ & $\begin{array}{l}\text { PNN reduction and dendritic spine and synaptic markers alterations occur in mice subjected to } \\
\text { chronic fluoxetine treatment; fluoxetine efficacy may occur through PNN degradation to promote } \\
\text { synaptic plasticity }\end{array}$ \\
\hline Smith et al., 2014 & $\begin{array}{l}\text { Substance Use Disorders } \\
\text { (SUD) }\end{array}$ & MMP activity is required for cocaine relapse in rodents \\
\hline Slaker et al., 2015 & $\begin{array}{l}\text { Substance Use Disorders } \\
\text { (SUD) }\end{array}$ & $\begin{array}{l}\text { PNNs in the rodent prefrontal cortex are required for acquisition and reconsolidation of cocaine } \\
\text { place preference }\end{array}$ \\
\hline $\begin{array}{l}\text { Carbo-Gas et al., } \\
2017\end{array}$ & $\begin{array}{l}\text { Substance Use Disorders } \\
\text { (SUD) }\end{array}$ & Cocaine induces differential PNN changes in cerebellar Golgi neurons and projection neurons \\
\hline $\begin{array}{l}\text { Donegan and } \\
\text { Lodge, } 2017\end{array}$ & $\begin{array}{l}\text { Major Depression Disorder } \\
\text { (MDD) }\end{array}$ & $\begin{array}{l}\text { PNN degradation in the ventral hippocampus of rats impairs the long-term efficacy of low dose } \\
\text { ketamine }\end{array}$ \\
\hline Riga et al., 2017 & $\begin{array}{l}\text { Major Depression Disorder } \\
\text { (MDD) }\end{array}$ & $\begin{array}{l}\text { Increased CSPG proteins and PNNs and decreased inhibitory postsynaptic currents occur in the } \\
\text { hippocampus of rats exposed to chronic social defeat stress }\end{array}$ \\
\hline Steullet et al., 2017 & Schizophrenia (SZ) & PNN and PVB neuron reduction occurs in the TRN of SZ subjects \\
\hline $\begin{array}{l}\text { Foscarin et al., } \\
2017\end{array}$ & Alzheimer's Disease (AD) & $\begin{array}{l}\text { CS- } 4 \text { levels are increased in aged in rats, associated with cognitive deficits and restricted axonal } \\
\text { growth }\end{array}$ \\
\hline Yang et al., 2017 & Alzheimer's Disease (AD) & $\begin{array}{l}\text { Antibody targeting of CS-4 temporarily improves novel object recognition memory in the P301S } \\
\text { mouse model of AD }\end{array}$ \\
\hline Egervari et al., 2017 & $\begin{array}{l}\text { Substance Use Disorders } \\
\text { (SUD) }\end{array}$ & $\begin{array}{l}\text { Altered gene expression of several ECM molecules in the striatum of people with heroin abuse, } \\
\text { including ACAN, CSPG4, MMP28, and ADAMTS3. }\end{array}$ \\
\hline
\end{tabular}


TABLE 2 | Continued

\begin{tabular}{|c|c|c|}
\hline Reference & $\begin{array}{l}\text { Psychiatric Disorder of } \\
\text { Interest }\end{array}$ & Summary of Findings \\
\hline $\begin{array}{l}\text { Vazquez-Sanroman } \\
\text { et al., } 2017\end{array}$ & $\begin{array}{l}\text { Substance Use Disorders } \\
\text { (SUD) }\end{array}$ & Nicotine self-administration alters PNNs in the rat ventral tegmental area and orbitofrontal cortex \\
\hline $\begin{array}{l}\text { Stefaniuk et al., } \\
2017\end{array}$ & $\begin{array}{l}\text { Substance Use Disorders } \\
\text { (SUD) }\end{array}$ & MMP-9 expression in the central amygdala regulates alcohol seeking behavior in rodents \\
\hline Bach et al., 2018 & $\begin{array}{l}\text { Post-Traumatic Stress } \\
\text { Disorder (PTSD) }\end{array}$ & Doxycycline, an MMP inhibitor, reduces arousal and fear memory in humans \\
\hline $\begin{array}{l}\text { Blacktop and Sorg, } \\
2018\end{array}$ & $\begin{array}{l}\text { Substance Use Disorders } \\
\text { (SUD) }\end{array}$ & $\begin{array}{l}\text { PNNs in the lateral hypothalamic area are necessary for cue induced reinstatement of cocaine } \\
\text { seeking behavior in rodents }\end{array}$ \\
\hline Alaiyed et al., 2019 & $\begin{array}{l}\text { Major Depression Disorder } \\
\text { (MDD) }\end{array}$ & $\begin{array}{l}\text { Venlafaxine, a serotonin/norepinephrine reuptake inhibitor, increases MMP-9 expression and } \\
\text { decreases PNN composition in rodents }\end{array}$ \\
\hline Alcaide et al., 2019 & $\begin{array}{l}\text { Major Depression Disorder } \\
\text { (MDD) }\end{array}$ & PNN density is unaltered in the dorsolateral prefrontal cortex of subjects with MDD \\
\hline Alaiyed et al., 2020 & $\begin{array}{l}\text { Major Depression Disorder } \\
(\mathrm{MDD})\end{array}$ & $\begin{array}{l}\text { Increased MMP-9 expression and reduced PNN composition after venlafaxine treatment are } \\
\text { associated with increased hippocampal gamma activity; venlafaxine efficacy may occur through } \\
\text { MMP-9 degradation of PNNs }\end{array}$ \\
\hline Crapser et al., 2020 & Alzheimer's Disease (AD) & Activated microglia engulf PNNs in AD; microglial depletion prevents PNN engulfment \\
\hline $\begin{array}{l}\text { Koskinen et al., } \\
2020\end{array}$ & $\begin{array}{l}\text { Major Depression Disorder } \\
\text { (MDD) }\end{array}$ & $\begin{array}{l}\text { Increases in hippocampal PNN intensity develop } 4-8 \text { weeks after social defeat stress, and coincide } \\
\text { with spatial memory deficits }\end{array}$ \\
\hline Nguyen et al., 2020 & Alzheimer's Disease (AD) & $\begin{array}{l}\text { IL-33 promotes ECM degradation for memory processing, and IL-33 is reduced with age in mice, } \\
\text { associated with memory deficits. Rescue of IL-33 signaling restores memory performance. }\end{array}$ \\
\hline $\begin{array}{l}\text { Pantazopoulos } \\
\text { et al., 2020b }\end{array}$ & Schizophrenia (SZ) & $\begin{array}{l}\text { In SZ, broad irregularities of ECM molecule gene expression, including CSPG core proteins, } \\
\text { chondroitin sulfate synthesis pathways, endogenous proteases, is associated with cognitive deficits }\end{array}$ \\
\hline Yu et al., 2020 & $\begin{array}{l}\text { Major Depression Disorder } \\
\text { (MDD) }\end{array}$ & $\begin{array}{l}\text { PNN density is reduced in the prelimbic cortex in rats exposed to chronic mild unpredictable stress } \\
\text { that display depression-like behavior }\end{array}$ \\
\hline Seney et al., 2020 & $\begin{array}{l}\text { Substance Use Disorders } \\
\text { (SUD) }\end{array}$ & $\begin{array}{l}\text { Altered gene expression of several ECM molecules in the DLPFC and VTA of human subjects with } \\
\text { opioid abuse. }\end{array}$ \\
\hline
\end{tabular}

\section{Major Depression and Bipolar Disorder}

Decreases of dendritic spines and synaptic markers have been reported in several brain regions in $\mathrm{BD}$ and $\mathrm{MDD}$, including the prefrontal cortex and hippocampus (Feyissa et al., 2009; Kang et al., 2012; Duric et al., 2013; Licznerski and Duman, 2013; Konopaske et al., 2014, 2015), and increased synaptic markers were reported in the lateral amygdala of subjects with $\mathrm{MD}$ (Karolewicz et al., 2009). Abnormalities in sleep and circadian rhythms have been consistently reported in these disorders (Leibenluft et al., 1996; Colombo et al., 1999; Jackson et al., 2003; Harvey et al., 2005; Armitage, 2007; Benedetti et al., 2007; McCarthy et al., 2012, 2013, 2016, 2019; Bunney and Bunney, 2013; Burton et al., 2013; Li et al., 2013; McClung, 2013; Palagini et al., 2013; Medina et al., 2014; Bunney et al., 2015; Pagani et al., 2016; Pantazopoulos et al., 2017, 2018; Nudell et al., 2019). These findings include diurnal rhythms in symptom severity, with anxiety and depression peaking in the morning (Murray et al., 2002; Murray, 2007, 2008; Wirz-Justice, 2008). Disrupted circadian rhythms in locomotor activity associated with several genetic factors have been reported in subjects with BD (Pagani et al., 2016). Disrupted gene expression diurnal rhythms have been reported in the brain of subjects with MDD (Bunney and Bunney, 2013; Li et al., 2013; Bunney et al., 2015). Altered diurnal rhythms of the anxiolytic neurotransmitter somatostatin were also reported in the amygdala of subjects with BD (Pantazopoulos et al., 2016), with decreased levels of somatostatin occurring in the morning, coinciding with reported increased severity of anxiety and depression (Murray et al., 2002; Murray, 2007, 2008; Wirz-Justice, 2008).

Animal models targeting the circadian system suggest that sleep and circadian rhythms are causative factors of mood disturbances, including mania, depression, and anxiety (Roybal et al., 2007; Dulcis et al., 2013; Landgraf et al., 2016). Conversely, chronic stress in mice also results in sleep and circadian rhythm disturbances reflective of findings in humans (Meerlo et al., 1996, 1997; Keeney et al., 2001; Henderson et al., 2017; Wells et al., 2017; Ota et al., 2018; Moravcova et al., 2020), without altering the molecular clock in the suprachiasmatic nucleus (Ota et al., 2018; Ota et al., 2020).

Pharmacological treatments, and genetic factors associated with treatment efficacy, point to a critical role of circadian rhythms in mood disorders. Gene association studies, including GWAS, identified gene variants for clock and clock controlled molecules associated with $\mathrm{BD}$ and lithium responsiveness (Nievergelt et al., 2006; Mansour et al., 2009; Sjoholm et al., 2010; Soria et al., 2010; McCarthy et al., 2012; McCarthy and Welsh, 2012; Pandey et al., 2012; Rybakowski, 2014; Bollettini et al., 2017; Suzuki et al., 2017). Furthermore, lithium and valproic acid, among the most common and effective treatments for mood disorders, alter core clock molecule expression and modulate the period length and amplitude of molecular circadian rhythms (Klemfuss, 1992; Abe et al., 2000; Yin et al., 2006; Johansson et al., 2011; Li et al., 2012; Noguchi et al., 2016). CACNA1C, one of the genes strongly associated with $\mathrm{BD}$, is involved in 
regulating circadian rhythms through L-type calcium channels (Ferreira et al., 2008; Sklar et al., 2008; Liu et al., 2011; Kumar et al., 2013; Fiorentino et al., 2014; Schmutz et al., 2014; Nudell et al., 2019). Growing evidence also indicates that CACNA1C is involved in efficacy of pharmacological therapies for $\mathrm{BD}$. For example, the ability of lithium to amplify circadian rhythms is dependent on L-type calcium channels including CACNA1C, and the effectiveness of lithium on restoring circadian amplitude in skin fibroblasts from patients with $\mathrm{BD}$ is dependent on genotype, including CACNA1C genotype (McCarthy et al., 2016; Nudell et al., 2019). Light therapy also represents a promising strategy for the treatment of mood disorders (Sit et al., 2007; Henriksen et al., 2014, 2016, 2020; Kaladchibachi and Fernandez, 2018; Sit et al., 2018). Specifically, the efficacy of bright light therapy for depression (Sit et al., 2007, 2018; Kaladchibachi and Fernandez, 2018) and blue light blocking treatment for mania (Henriksen et al., 2014, 2016, 2020) suggest that patient specific approaches targeting the circadian system are promising therapeutic strategies.

Several lines of evidence suggest that PNNs are critically involved in disease symptoms and treatment efficacy in $\mathrm{BD}$ and MDD. Chronic social defeat stress in rats, commonly used to model depression, results in increased CSPG proteins and PNN numbers in the hippocampus, together with reduced frequency of inhibitory postsynaptic currents (Riga et al., 2017). These PNN changes emerge 4-8 weeks after social defeat stress, and coincide with the emergence of later stage spatial memory deficits (Koskinen et al., 2020). Chronic social defeat also results in changes in sleep, circadian rhythm, and clock gene measures in mice that persist afterward (Wells et al., 2017), suggesting that PNN alterations may be influenced by circadian rhythm disruption. The antidepressants venlafaxine, a serotonin/norepinephrine reuptake inhibitor, has been shown to increase MMP-9 expression in the rodent brain and reduce PNN composition (Alaiyed et al., 2019), and subjects with MDD with antidepressant treatment have increased MMP-9 expression in the dorsolateral prefrontal cortex compared to control subjects (Alaiyed et al., 2020). These changes in MMP-9 and PNNs following venlafaxine treatment were also associated with increased hippocampal gamma activity, suggesting that antidepressant efficacy of venlafaxine may occur in part through MMP-9 reduction of PNN composition (Alaiyed et al., 2020). Chronic treatment with the antidepressant fluoxetine has also been shown to reduce PNNs in mice, along with alterations in synaptic markers and dendritic spines (Guirado et al., 2014), providing further support that antidepressant efficacy may in part be due to promotion of synaptic plasticity through PNN degradation. Furthermore, chemical degradation of PNNs in the ventral hippocampus impairs the long-term antidepressant effect of low dose ketamine in rats (Donegan and Lodge, 2017), suggesting that PNN composition deficits, and/or alterations in PNN composition rhythms in these disorders, may impact treatment efficacy.

Perineuronal net deficits have been reported in the dorsolateral prefrontal cortex, amygdala and TRN in BD (Pantazopoulos et al., 2015; Steullet et al., 2017; Alcaide et al., 2019). Despite the evidence from rodent studies strongly suggesting that PNNs are altered in depression, and that antidepressant efficacy in part is associated with PNN degradation, current evidence for PNN alterations in MDD is limited. Currently, one human postmortem study reported lack of changes in PNN density in the dorsolateral prefrontal cortex of subjects with MDD (Alcaide et al., 2019). Disruption of PNNs in these disorders may alter rhythms of synaptic plasticity and in turn contribute to shared synaptic deficits (Penzes et al., 2011; Glausier and Lewis, 2013; Shelton et al., 2015; MacDonald et al., 2017). Such deficits may arise from disrupted memory consolidation processes allowing for decreased synaptic formation and/or increased synaptic pruning in brain regions involved in emotional memory processing.

\section{Post-traumatic Stress Disorder}

Enhanced fear memories are a core feature of post-traumatic disorder (PTSD) (Parsons and Ressler, 2013). Similarly, sleep disruption and nightmares are common symptoms in people with PTSD, and are associated with heightened strength of fear memories (Ross et al., 1989; Raskind et al., 2007; Thompson et al., 2008; Harb et al., 2012; Brownlow et al., 2015). Studies suggest that these sleep disturbances contribute to the persistent heightened fear memories in this disorder. For example, frequent nightmares and SD in patients suffering from PTSD is associated with impaired extinction of fear memories (Mellman et al., 2002). Sleep deprivation, particularly decreased REM sleep, impairs fear extinction learning in both rodents and humans (Silvestri, 2005; Fu et al., 2007). In contrast, studies suggest that sleep deprivation early on following a traumatic experience may help to alleviate the strength of fear memories that contribute to PTSD (Wagner et al., 2006; Kuriyama et al., 2010; Cohen et al., 2012). Sleep after learning enhances emotional memories in humans for up to 4 years (Wagner et al., 2006), and sleep deprivation reduces emotional memories in human subjects (Kuriyama et al., 2010). Rodent studies provide additional support and point to potential mechanisms for this process. For example, sleep deprivation reduces fear memory and alters glucocorticoid signaling and dendritic spines in the hippocampus (Cohen et al., 2012).

Chronic stress can serve as a predisposing factor for PTSD (Davidson et al., 1991; Breslau et al., 1999; Chetty et al., 2014; Meyer et al., 2014; Brockie et al., 2015; Yousufzai et al., 2018). Rodent models of chronic stress suggest that predisposition may be due in part to changes in dendritic spines. Chronic stress in rodents decreases dendritic spines in the hippocampus in comparison to increased spines in the amygdala, which may underlie generalization of fear response (Vyas et al., 2002). Similarly, chronic stress was shown to increase ghrelingrowth hormone signaling (Meyer et al., 2014), which can increase amygdala dendritic spines and predispose these neurons to encode fear memories (Gisabella et al., 2016). Studies of humans with chronic stress showing provide further support for the neurocircuitry effects of chronic stress suggested by rodent studies. Subjects with chronic stress display decreased hippocampal synaptic markers and hippocampal volume (Lange and Irle, 2004; Videbech and Ravnkilde, 2004; Smith, 2005; Soetanto et al., 2010). In comparison, increased amygdala volume and activity (Bremner et al., 2000; Frodl et al., 2002; 
Drevets, 2003; Lange and Irle, 2004; Tottenham et al., 2010) are reported in chronic stress subjects, possibly reflecting increased dendritic spines. Several studies suggest that SD following emotional learning may be a promising preventative measure for PTSD (Kuriyama et al., 2010; Cohen et al., 2012, 2017).

Perineuronal nets are strongly involved in fear memory processing (Gogolla et al., 2009; Banerjee et al., 2017). Regulation of PNN composition represent a therapeutic strategy for weaking fear memories that are enhanced in people suffering from PTSD. Disruption of molecular processes involved in PNN rhythms may represent one of the potential mechanisms through which sleep deprivation may impact memory consolidation (Kuriyama et al., 2010; Cohen et al., 2012, 2017) and may possible therapeutic approach for alleviating the strength of fear memories contributing to PTSD. Intracerebroventricular administration of the MMP inhibitor FN-439 has been shown to disrupt fear memory reconsolidation in rodents (Brown et al., 2009), and MMP-9 knockout mice display deficits in LTP and fear memory (Nagy et al., 2006). Furthermore, the MMP inhibitor doxycycline reduces fear memory and arousal in humans (Bach et al., 2018). These findings suggest that inhibition of endogenous proteases that may block regulation of PNN composition and other ECM components during sleep may impair normally occurring consolidation processes during sleep that strengthen emotional memories following a traumatic experience. Subsequently, the development of nightmares and sleep disturbances may impact the ability to extinguish fear memories later on. Further regarding the timing of administration of endogenous protease inhibitors, both in terms of distance from the traumatic event and as well as timing of the sleep-wake cycle will provide insight into the potential ECM protease inhibitors as therapeutic strategies for PTSD.

\section{Substance Abuse Disorders}

Sleep disturbances are associated in a bi-directional manner with the cycle of impulsivity and cognitive deficits in substance use disorders (Koob and Colrain, 2020). Drugs of abuse cause direct phase-shifting of circadian rhythm and alter sleep architecture when used shortly before sleep (Lin et al., 2000; Wang and Teichtahl, 2007; Colrain et al., 2014; Narishige et al., 2014). A hallmark of SUD is abnormalities and inconsistency in chronotype, and adolescent sleep deprivation is a risk factor for developing a substance use disorder later in life (Pasch et al., 2012). Preclinical studies investigating the impact of sleep and circadian rhythm abnormalities on behavioral responses to drugs of abuse indicate that sleep restriction increases reward seeking. REM sleep deprivation enhances ethanol self-administration (Aalto and Kiianmaa, 1986). Conversely, 6 h of sleep deprivation following re-exposure to morphine reward impairs reward memory reconsolidation (Shi et al., 2011), indicating sleep plays a central role in the regulation of reward memory consolidation.

Extracellular matrix molecules alterations have been extensively described as a key feature of reward memory processing (Xue et al., 2014; Slaker et al., 2015; Blacktop and Sorg, 2018). Altered expression of ECM molecules has been reported in several human postmortem brain studies, including in the striatum of people with heroin abuse (Egervari et al., 2017)and in the dorsolateral prefrontal cortex and ventral tegmental area of subjects with opioid abuse (Seney et al., 2020). PNNs are well represented in neural circuits involved in emotion processing and critically involved in the regulation of fear and reward memories (Gogolla et al., 2009; Slaker et al., 2015; Banerjee et al., 2017; Lasek et al., 2018). Alteration in PNNs has been described as a key feature in addiction (Xue et al., 2014; Slaker et al., 2015; Vazquez-Sanroman et al., 2017; Blacktop and Sorg, 2018). Ablation of PNNs in the corticostriatal circuit significantly weakens drug reward memories, indicating that broad PNN and ECM density increases are a molecular signature of addiction (Brown et al., 2007). While there are increases in PNN densities after prolonged drug use, initial acquisition of drug memories appears to rely on the activity of MMPs to degrade PNN components and allow for formation of new synapses (Wright et al., 2003; Mizoguchi et al., 2007; Smith et al., 2011, 2014; Kovatsi et al., 2013; Natarajan et al., 2013; Stefaniuk et al., 2017). Modulation of PNNs is necessary for reward memory acquisition, and prolonged re-activation of drug-associated engrams reconsolidates PNN components, stronger than at baseline, to stabilize and potentiate these synapses (Van den Oever et al., 2010; Chen et al., 2015; Slaker et al., 2015, 2018; Blacktop et al., 2017; Carbo-Gas et al., 2017). For example, broad spectrum MMP inhibition disrupts both acquisition and consolidation of cocaine reward memory in rats (Brown et al., 2007). Furthermore, a genetic polymorphism for MMP-9 is associated with alcoholism (Samochowiec et al., 2010). Circadian rhythms in PNN composition may have a significant impact in reward memory processing. PNN composition decreases during the inactive phase may contribute to enhanced reward sensitivity in the evening reported in human subjects (Murray et al., 2009; Pantazopoulos et al., 2020a). PNN digestion in the ventral hippocampus by chondroitinase $\mathrm{ABC}$ enhances dopamine VTA activity and amphetamine response (Shah and Lodge, 2013), providing further support that PNN composition decreases during the inactive phase may contribute to enhanced reward sensitivity in the evening in humans (Murray et al., 2009). Disruption of PNN composition rhythms in turn may impair the memory consolidation processes that normally occur during sleep (Tononi and Cirelli, 2006; Rasch and Born, 2013; Tononi and Cirelli, 2014; Dudai et al., 2015), and thus may represent a promising therapeutic target for drug addiction.

\section{AGING AND ALZHEIMER'S DISEASE}

Synaptic deficits are a hallmark of aging and Alzheimer's Disease (DeKosky and Scheff, 1990; Terry et al., 1991; Scheff and Price, 1993; Kristiansen et al., 2010; Schmitt et al., 2010). Disrupted sleep and circadian rhythm have also been consistently described with age (Bliwise, 1993; Van Cauter et al., 2000; Huang et al., 2002; Harper et al., 2005; Chen et al., 2016) and are key features of Alzheimer's Disease (Witting et al., 1990; Volicer et al., 2001; Harper et al., 2005; Ju et al., 2013; Musiek et al., 2018). For example, circadian rhythm amplitude decreases with age as people shift to an early bird chronotype (Huang et al., 2002). Aging is also characterized by increased insomnia and 
fragmented sleep (Bliwise, 1993; Van Cauter et al., 2000). Alterations are also observed in expression of genes and proteins in the brain involved in the regulation of circadian rhythms (Hofman et al., 1996; Wang et al., 2015; Chen et al., 2016). Diurnal expression rhythms of clock genes in the brain are impaired with age in humans (Chen et al., 2016). SCN neurons expressing the neurotransmitter vasoactive intestinal peptide (VIP), which is important to maintaining strength of circadian rhythmicity (Aton et al., 2005; Pantazopoulos et al., 2010a; Jones et al., 2018; Mazuski et al., 2018, 2020), are decreased with age in the human SCN (Hofman et al., 1996), and are correlated with the strength of locomotor circadian rhythms recorded prior to death (Wang et al., 2015). Disruptions in molecular circadian rhythms with age may also contribute to disruption of ECM processes involved in synaptic regulation during sleep, thus impairing memory consolidation processes. Impaired sleep spindles and memory consolidation with age support this hypothesis (Guazzelli et al., 1986; DeKosky and Scheff, 1990; Terry et al., 1991; Scheff and Price, 1993; Crowley et al., 2002; Knoblauch et al., 2005).

Decreases of PNNs have been reported in $\mathrm{AD}$ patients and mouse models (Baig et al., 2005; Crapser et al., 2020). A recent study combining analysis of human postmortem brain samples and an animal model of AD indicates that activated microglia engulf PNNs in $\mathrm{AD}$, and microglial depletion prevents this engulfment (Crapser et al., 2020). In contrast, other studies suggest that PNNs are protective factors for neurons in $\mathrm{AD}$ (Morawski et al., 2004, 2010). Evidence regarding changes in levels of sulfated CS point to more consistent findings in $\mathrm{AD}$ and aging. CS-4 sulfation inhibits axonal growth (Smith-Thomas et al., 1995; Wang et al., 2008), whereas CS-6 is much more permissive for axonal growth (Lin et al., 2011; Miyata et al., 2012), in part through promoting degradation of the major PNN component aggrecan by ADAMTS (Miyata and Kitagawa, 2016). The ratio of CS-4/CS- 6 increases with age, suggesting that this increase in CS-4 contributes to restricted plasticity in aging (Foscarin et al., 2017). Preclinical studies in mice suggest that targeting CS-4 may improve cognition in Alzheimer's disease (Yang et al., 2017). Recent work demonstrates that neurons

\section{REFERENCES}

Aalto, J., and Kiianmaa, K. (1986). REM-sleep deprivation-induced increase in ethanol intake: role of brain monoaminergic neurons. Alcohol 3, 377-381. doi: 10.1016/0741-8329(86)90057-1

Abe, M., Herzog, E. D., and Block, G. D. (2000). Lithium lengthens the circadian period of individual suprachiasmatic nucleus neurons. Neuroreport 11, 32613264.

Abi-Dargham, A., Rodenhiser, J., Printz, D., Zea-Ponce, Y., Gil, R., Kegeles, L. S., et al. (2000). Increased baseline occupancy of D2 receptors by dopamine in schizophrenia. Proc. Natl. Acad. Sci. U.S.A. 97, 8104-8109. doi: 10.1073/pnas. 97.14.8104

Abi-Dargham, A., van de Giessen, E., Slifstein, M., Kegeles, L. S., and Laruelle, M. (2009). Baseline and amphetamine-stimulated dopamine activity are related in drug-naive schizophrenic subjects. Biol. Psychiatry 65, 1091-1093. doi: 10.1016/ j.biopsych.2008.12.007

Alaiyed, S., Bozzelli, P. L., Caccavano, A., Wu, J. Y., and Conant, K. (2019). Venlafaxine stimulates PNN proteolysis and MMP-9-dependent enhancement signal to microglia through IL-33 to stimulate engulfment of ECM, which promotes synapse formation (Nguyen et al., 2020). In aged animals this process is impaired due to less IL-33, which results in reduced synapses and impaired spatial memory resolution (Nguyen et al., 2020). Restoration of IL-33 signaling restores younger numbers of dendritic spines and spatial memory performance (Nguyen et al., 2020). This evidence is in-line with studies that suggest CS- 4 accumulation with age restricts synaptic plasticity and contributes to memory deficits (Foscarin et al., 2017; Yang et al., 2017). Disruption of circadian rhythms with age may impair circadian regulation of PNNs, contributing to memory consolidation and synaptic deficits reported in aging and Alzheimer's Disease (Guazzelli et al., 1986; DeKosky and Scheff, 1990; Terry et al., 1991; Scheff and Price, 1993; Crowley et al., 2002; Knoblauch et al., 2005; Kristiansen et al., 2010; Schmitt et al., 2010).

\section{CONCLUSION}

In summary, sleep and synaptic dysfunction is present across psychiatric disorders. Extracellular matrix molecules are involved in synaptic regulation and their expression is disrupted in these disorders. Recent studies point to the critical involvement of ECM molecules including PNNs in memory consolidation, thus ECM molecules represent promising therapeutic targets for memory consolidation dysfunction in psychiatric disorders.

\section{AUTHOR CONTRIBUTIONS}

All authors contributed to literature review and manuscript writing. BG and HP wrote the first draft and edited the manuscript.

\section{FUNDING}

This work was funded by NIH R21MH117460. of gamma power; relevance to antidepressant efficacy. J. Neurochem. 148, 810-821. doi: 10.1111/jnc.14671

Alaiyed, S., McCann, M., Mahajan, G., Rajkowska, G., Stockmeier, C. A., Kellar, K. J., et al. (2020). Venlafaxine stimulates an MMP-9-dependent increase in excitatory/inhibitory balance in a stress model of depression. J. Neurosci. 40, 4418-4431. doi: 10.1523/JNEUROSCI.2387-19.2020

Alcaide, J., Guirado, R., Crespo, C., Blasco-Ibanez, J. M., Varea, E., Sanjuan, J., et al. (2019). Alterations of perineuronal nets in the dorsolateral prefrontal cortex of neuropsychiatric patients. Int. J. Bipolar. Disord. 7:24. doi: 10.1186/s40345-0190161-0

Anand, A., Barkay, G., Dzemidzic, M., Albrecht, D., Karne, H., Zheng, Q. H., et al. (2011). Striatal dopamine transporter availability in unmedicated bipolar disorder. Bipolar. Disord. 13, 406-413. doi: 10.1111/j.1399-5618.2011.0 0936.x

Armitage, R. (2007). Sleep and circadian rhythms in mood disorders. Acta Psychiatr. Scand. Suppl. 433, 104-115. doi: 10.1111/j.1600-0447.2007.00968.x

Aton, S. J., Colwell, C. S., Harmar, A. J., Waschek, J., and Herzog, E. D. (2005). Vasoactive intestinal polypeptide mediates circadian rhythmicity and 
synchrony in mammalian clock neurons. Nat. Neurosci. 8, 476-483. doi: 10. 1038/nn1419

Bach, D. R., Tzovara, A., and Vunder, J. (2018). Blocking human fear memory with the matrix metalloproteinase inhibitor doxycycline. Mol. Psychiatry 23, 1584-1589. doi: 10.1038/mp.2017.65

Baig, S., Wilcock, G. K., and Love, S. (2005). Loss of perineuronal net $\mathrm{N}$-acetylgalactosamine in Alzheimer's disease. Acta Neuropathol. 110, 393-401. doi: 10.1007/s00401-005-1060-2

Bajor, M., and Kaczmarek, L. (2013). Proteolytic remodeling of the synaptic cell adhesion molecules (CAMs) by metzincins in synaptic plasticity. Neurochem. Res. 38, 1113-1121. doi: 10.1007/s11064-012-0919-6

Banerjee, S. B., Gutzeit, V. A., Baman, J., Aoued, H. S., Doshi, N. K., Liu, R. C., et al. (2017). Perineuronal nets in the adult sensory cortex are necessary for fear learning. Neuron 95, 169-179. doi: 10.1016/j.neuron.2017.06.007

Baran, B., Karahanoglu, F. I., Mylonas, D., Demanuele, C., Vangel, M., Stickgold, R., et al. (2019). Increased thalamocortical connectivity in schizophrenia correlates with sleep spindle deficits: evidence for a common pathophysiology. Biol. Psychiatry Cogn. Neurosci. Neuroimag. 4, 706-714. doi: 10.1016/j.bpsc.2019.04. 012

Bellesi, M., de Vivo, L., Chini, M., Gilli, F., Tononi, G., and Cirelli, C. (2017). Sleep loss promotes astrocytic phagocytosis and microglial activation in mouse cerebral cortex. J. Neurosci. 37, 5263-5273. doi: 10.1523/JNEUROSCI.3981-16. 2017

Belujon, P., and Grace, A. A. (2017). Dopamine system dysregulation in major depressive disorders. Int. J. Neuropsychopharmacol. 20, 1036-1046. doi: 10. 1093/ijnp/pyx056

Benchenane, K., Peyrache, A., Khamassi, M., Tierney, P. L., Gioanni, Y., Battaglia, F. P., et al. (2010). Coherent theta oscillations and reorganization of spike timing in the hippocampal- prefrontal network upon learning. Neuron 66, 921-936. doi: 10.1016/j.neuron.2010.05.013

Bendor, D., and Wilson, M. A. (2012). Biasing the content of hippocampal replay during sleep. Nat. Neurosci. 15, 1439-1444. doi: 10.1038/nn.3203

Benedetti, F., Barbini, B., Colombo, C., and Smeraldi, E. (2007). Chronotherapeutics in a psychiatric ward. Sleep. Med. Rev. 11, 509-522. doi: 10.1016/j.smrv.2007.06.004

Berdenis van Berlekom, A., Muflihah, C. H., Snijders, G., MacGillavry, H. D., Middeldorp, J., Hol, E. M., et al. (2020). Synapse pathology in schizophrenia: a meta-analysis of postsynaptic elements in postmortem brain studies. Schizophr. Bull. 46, 374-386. doi: 10.1093/schbul/sbz060

Berke, J. D., and Hyman, S. E. (2000). Addiction, dopamine, and the molecular mechanisms of memory. Neuron 25, 515-532. doi: 10.1016/s0896-6273(00) 81056-9

Bertocchi, I., Mele, P., Ferrero, G., Oberto, A., Carulli, D., and Eva, C. (2020). NPYY1 receptor signaling controls spatial learning and perineuronal net expression. Neuropharmacology 184:108425. doi: 10.1016/j.neuropharm.2020.108425

Beurdeley, M., Spatazza, J., Lee, H. H., Sugiyama, S., Bernard, C., Di Nardo, A. A., et al. (2012). Otx2 binding to perineuronal nets persistently regulates plasticity in the mature visual cortex. J. Neurosci. 32, 9429-9437. doi: 10.1523/ JNEUROSCI.0394-12.2012

Blacktop, J. M., and Sorg, B. A. (2018). Perineuronal nets in the lateral hypothalamus area regulate cue-induced reinstatement of cocaine-seeking behavior. Neuropsychopharmacology 44, 850-858. doi: 10.1038/s41386-0180212-8

Blacktop, J. M., Todd, R. P., and Sorg, B. A. (2017). Role of perineuronal nets in the anterior dorsal lateral hypothalamic area in the acquisition of cocaine-induced conditioned place preference and self-administration. Neuropharmacology 118, 124-136. doi: 10.1016/j.neuropharm.2017.03.018

Bliwise, D. L. (1993). Sleep in normal aging and dementia. Sleep 16, 40-81. doi: $10.1093 /$ sleep/16.1.40

Blosa, M., Sonntag, M., Jager, C., Weigel, S., Seeger, J., Frischknecht, R., et al. (2015). The extracellular matrix molecule brevican is an integral component of the machinery mediating fast synaptic transmission at the calyx of Held. J. Physiol. 593, 4341-4360. doi: 10.1113/JP270849

Bollettini, I., Melloni, E. M., Aggio, V., Poletti, S., Lorenzi, C., Pirovano, A., et al. (2017). Clock genes associate with white matter integrity in depressed bipolar patients. Chronobiol. Int. 34, 212-224. doi: 10.1080/07420528.2016.1260026

Bolós, M., Perea, J. R., Terreros-Roncal, J., Pallas-Bazarra, N., Jurado-Arjona, J., Ávila, J., et al. (2018). Absence of microglial CX3CR1 impairs the synaptic integration of adult-born hippocampal granule neurons. Brain Behav. Immun. 68, 76-89. doi: 10.1016/j.bbi.2017.10.002

Brakebusch, C., Seidenbecher, C. I., Asztely, F., Rauch, U., Matthies, H., Meyer, H., et al. (2002). Brevican-deficient mice display impaired hippocampal CA1 longterm potentiation but show no obvious deficits in learning and memory. Mol. Cell Biol. 22, 7417-7427.

Bremner, J. D., Narayan, M., Anderson, E. R., Staib, L. H., Miller, H. L., and Charney, D. S. (2000). Hippocampal volume reduction in major depression. Am. J. Psychiatry 157, 115-118. doi: 10.1176/ajp.157.1.115

Breslau, N., Chilcoat, H. D., Kessler, R. C., and Davis, G. C. (1999). Previous exposure to trauma and PTSD effects of subsequent trauma: results from the Detroit Area Survey of Trauma. Am. J. Psychiatry 156, 902-907. doi: 10.1176/ ajp.156.6.902

Bridi, M. C. D., Zong, F. J., Min, X., Luo, N., Tran, T., Qiu, J., et al. (2020). Daily oscillation of the excitation-inhibition balance in visual cortical circuits. Neuron 105, 621-629.e624. doi: 10.1016/j.neuron.2019.11.011

Brockie, T. N., Dana-Sacco, G., Wallen, G. R., Wilcox, H. C., and Campbell, J. C. (2015). The relationship of adverse childhood experiences to PTSD, depression, poly-drug use and suicide attempt in reservation-based native american adolescents and young adults. Am. J. Commun. Psychol. 55, 411-421. doi: 10.1007/s10464-015-9721-3

Brown, T. E., Forquer, M. R., Cocking, D. L., Jansen, H. T., Harding, J. W., and Sorg, B. A. (2007). Role of matrix metalloproteinases in the acquisition and reconsolidation of cocaine-induced conditioned place preference. Learn. Mem. 14, 214-223. doi: 10.1101/lm.476207

Brown, T. E., Wilson, A. R., Cocking, D. L., and Sorg, B. A. (2009). Inhibition of matrix metalloproteinase activity disrupts reconsolidation but not consolidation of a fear memory. Neurobiol. Learn. Mem. 91, 66-72. doi: 10.1016/j.nlm.2008.09.003

Brownlow, J. A., Harb, G. C., and Ross, R. J. (2015). Treatment of sleep disturbances in post-traumatic stress disorder: a review of the literature. Curr. Psychiatry Rep. 17:41. doi: 10.1007/s11920-015-0587-8

Bukalo, O., Schachner, M., and Dityatev, A. (2001). Modification of extracellular matrix by enzymatic removal of chondroitin sulfate and by lack of tenascin$\mathrm{R}$ differentially affects several forms of synaptic plasticity in the hippocampus. Neuroscience 104, 359-369.

Bunney, B. G., and Bunney, W. E. (2013). Mechanisms of rapid antidepressant effects of sleep deprivation therapy: clock genes and circadian rhythms. Biol. Psychiatry 73, 1164-1171. doi: 10.1016/j.biopsych.2012.07.020

Bunney, B. G., Li, J. Z., Walsh, D. M., Stein, R., Vawter, M. P., Cartagena, P., et al. (2015). Circadian dysregulation of clock genes: clues to rapid treatments in major depressive disorder. Mol. Psychiatry 20, 48-55. doi: 10.1038/mp.2014.138

Burton, C., McKinstry, B., Szentagotai Tatar, A., Serrano-Blanco, A., Pagliari, C., and Wolters, M. (2013). Activity monitoring in patients with depression: a systematic review. J. Affect. Disord. 145, 21-28. doi: 10.1016/j.jad.2012.07.001

Bushey, D., Tononi, G., and Cirelli, C. (2011). Sleep and synaptic homeostasis: structural evidence in Drosophila. Science 332, 1576-1581. doi: 10.1126/science. 1202839

Butler, H. E. (1921). Quintillian's Insitutio Oratoria. Cambridge, MA: Harvard University Press.

Cahoy, J. D., Emery, B., Kaushal, A., Foo, L. C., Zamanian, J. L., Christopherson, K. S., et al. (2008). A transcriptome database for astrocytes, neurons, and oligodendrocytes: a new resource for understanding brain development and function. J. Neurosci. 28, 264-278. doi: 10.1523/JNEUROSCI.4178-07.2008

Carbo-Gas, M., Moreno-Rius, J., Guarque-Chabrera, J., Vazquez-Sanroman, D., Gil-Miravet, I., Carulli, D., et al. (2017). Cerebellar perineuronal nets in cocaineinduced pavlovian memory: Site matters. Neuropharmacology 125, 166-180. doi: 10.1016/j.neuropharm.2017.07.009

Carceller, H., Guirado, R., Ripolles-Campos, E., Teruel-Marti, V., and Nacher, J. (2020). Perineuronal nets regulate the inhibitory perisomatic input onto Parvalbumin interneurons and gamma activity in the prefrontal cortex. J. Neurosci. 40, 5008-5018. doi: 10.1523/JNEUROSCI.0291-20.2020

Chaudhury, D., Wang, L. M., and Colwell, C. S. (2005). Circadian regulation of hippocampal long-term potentiation. J. Biol. Rhythms 20, 225-236. doi: 10. 1177/0748730405276352

Chelini, G., Pantazopoulos, H., Durning, P., and Berretta, S. (2018). The tetrapartite synapse: a key concept in the pathophysiology of schizophrenia. Eur. Psychiatry 50, 60-69. doi: 10.1016/j.eurpsy.2018.02.003 
Chellappa, S. L., Gaggioni, G., Ly, J. Q., Papachilleos, S., Borsu, C., Brzozowski, A., et al. (2016). Circadian dynamics in measures of cortical excitation and inhibition balance. Sci. Rep. 6:33661. doi: 10.1038/srep33661

Chen, C. Y., Logan, R. W., Ma, T., Lewis, D. A., Tseng, G. C., Sibille, E., et al. (2016). Effects of aging on circadian patterns of gene expression in the human prefrontal cortex. Proc. Natl. Acad. Sci. U.S.A. 113, 206-211. doi: 10.1073/pnas. 1508249112

Chen, C., Hardy, M., Zhang, J., LaHoste, G. J., and Bazan, N. G. (2006). Altered NMDA receptor trafficking contributes to sleep deprivation-induced hippocampal synaptic and cognitive impairments. Biochem. Biophys. Res. Commun. 340, 435-440. doi: 10.1016/j.bbrc.2005.12.021

Chen, H., He, D., and Lasek, A. W. (2015). Repeated binge drinking increases perineuronal nets in the insular cortex. Alcohol. Clin. Exp. Res. 39, 1930-1938. doi: $10.1111 /$ acer. 12847

Chetty, S., Friedman, A. R., Taravosh-Lahn, K., Kirby, E. D., Mirescu, C., Guo, F., et al. (2014). Stress and glucocorticoids promote oligodendrogenesis in the adult hippocampus. Mol. Psychiatry 19, 1275-1283. doi: 10.1038/mp.2013.190

Christensen, A. C., Lensjo, K. K., Lepperod, M. E., Dragly, S. A., Sutterud, H., Blackstad, J. S., et al. (2021). Perineuronal nets stabilize the grid cell network. Nat. Commun. 12:253. doi: 10.1038/s41467-020-20241-w

Cirelli, C. (2005). A molecular window on sleep: changes in gene expression between sleep and wakefulness. Neuroscientist 11, 63-74. doi: 10.1177/ 1073858404270900

Cohen, S., Kaplan, Z., Zohar, J., and Cohen, H. (2017). Preventing sleep on the first resting phase following a traumatic event attenuates anxiety-related responses. Behav. Brain Res. 320, 450-456. doi: 10.1016/j.bbr.2016.10.039

Cohen, S., Kozlovsky, N., Matar, M. A., Kaplan, Z., Zohar, J., and Cohen, H. (2012). Post-exposure sleep deprivation facilitates correctly timed interactions between glucocorticoid and adrenergic systems, which attenuate traumatic stress responses. Neuropsychopharmacology 37, 2388-2404. doi: 10.1038/npp. 2012.94

Colombo, C., Benedetti, F., Barbini, B., Campori, E., and Smeraldi, E. (1999). Rate of switch from depression into mania after therapeutic sleep deprivation in bipolar depression. Psychiatry Res. 86, 267-270. doi: 10.1016/s0165-1781(99) 00036-0

Colrain, I. M., Nicholas, C. L., and Baker, F. C. (2014). Alcohol and the sleeping brain. Handb Clin. Neurol. 125, 415-431. doi: 10.1016/B978-0-444-62619-6. 00024-0

Cousins, D. A., Butts, K., and Young, A. H. (2009). The role of dopamine in bipolar disorder. Bipolar. Disord. 11, 787-806. doi: 10.1111/j.1399-5618.2009.00760.x

Crapser, J. D., Spangenberg, E. E., Barahona, R. A., Arreola, M. A., Hohsfield, L. A., and Green, K. N. (2020). Microglia facilitate loss of perineuronal nets in the Alzheimer's disease brain. EBioMedicine 58:102919. doi: 10.1016/j.ebiom.2020. 102919

Cross-Disorder Group of the Psychiatric Genomics Consortium, Lee, S. H., Ripke, S., Neale, B. M., Faraone, S. V., Purcell, S. M., et al. (2013). Genetic relationship between five psychiatric disorders estimated from genome-wide SNPs. Nat. Genet. 45, 984-994. doi: 10.1038/ng.2711

Crowley, K., Trinder, J., Kim, Y., Carrington, M., and Colrain, I. M. (2002). The effects of normal aging on sleep spindle and K-complex production. Clin. Neurophysiol. 113, 1615-1622. doi: 10.1016/s1388-2457(02)00237-7

Csillik, B., Mihaly, A., Krisztin-Peva, B., Chadaide, Z., Samsam, M., KnyiharCsillik, E., et al. (2005). GABAergic parvalbumin-immunoreactive large calyciform presynaptic complexes in the reticular nucleus of the rat thalamus. J. Chem. Neuroanat. 30, 17-26. doi: 10.1016/j.jchemneu.2005.03.010

D’Agostino, A., Castelnovo, A., Cavallotti, S., Casetta, C., Marcatili, M., Gambini, O., et al. (2018). Sleep endophenotypes of schizophrenia: slow waves and sleep spindles in unaffected first-degree relatives. NPJ Schizophr. 4:2. doi: 10.1038/ s41537-018-0045-9

Davidson, J. R., Hughes, D., Blazer, D. G., and George, L. K. (1991). Post-traumatic stress disorder in the community: an epidemiological study. Psychol. Med. 21, 713-721. doi: 10.1017/s0033291700022352

de Vivo, L., Bellesi, M., Marshall, W., Bushong, E. A., Ellisman, M. H., Tononi, G., et al. (2017). Ultrastructural evidence for synaptic scaling across the wake/sleep cycle. Science 355, 507-510. doi: 10.1126/science.aah5982

DeKosky, S. T., and Scheff, S. W. (1990). Synapse loss in frontal cortex biopsies in Alzheimer's disease: correlation with cognitive severity. Ann. Neurol. 27, 457-464. doi: 10.1002/ana.410270502
Delorme, J. E., Kodoth, V., and Aton, S. J. (2019). Sleep loss disrupts Arc expression in dentate gyrus neurons. Neurobiol. Learn. Mem. 160, 73-82. doi: 10.1016/j. nlm.2018.04.006

Delorme, J., Wang, L., Kodoth, V., Wang, Y., Ma, J., Jiang, S., et al. (2020). Learning and sleep have divergent effects on cytosolic and membrane-associated ribosomal mRNA profiles in hippocampal neurons. bioRxiv [Preprint]. doi: 10.1101/2020.07.27.221218

Delorme, T. C., Srivastava, L. K., and Cermakian, N. (2020). Are circadian disturbances a core pathophysiological component of schizophrenia? J. Biol. Rhythms 35, 325-339. doi: 10.1177/0748730420929448

Diering, G. H., Nirujogi, R. S., Roth, R. H., Worley, P. F., Pandey, A., and Huganir, R. L. (2017). Homerla drives homeostatic scaling-down of excitatory synapses during sleep. Science 355, 511-515. doi: 10.1126/science.aai8355

Dobbertin, A., Rhodes, K. E., Garwood, J., Properzi, F., Heck, N., Rogers, J. H., et al. (2003). Regulation of RPTPbeta/phosphacan expression and glycosaminoglycan epitopes in injured brain and cytokine-treated glia. Mol. Cell. Neurosci. 24, 951-971.

Donegan, J. J., and Lodge, D. J. (2017). Hippocampal perineuronal nets are required for the sustained antidepressant effect of ketamine. Int. J. Neuropsychopharmacol. 20, 354-358. doi: 10.1093/ijnp/pyw095

Dorph-Petersen, K. A., Delevich, K. M., Marcsisin, M. J., Zhang, W., Sampson, A. R., Gundersen, H. J., et al. (2009). Pyramidal neuron number in layer 3 of primary auditory cortex of subjects with schizophrenia. Brain Res. 1285, 42-57. doi: 10.1016/j.brainres.2009.06.019

Drevets, W. C. (2003). Neuroimaging abnormalities in the amygdala in mood disorders. Ann. N. Y. Acad. Sci. 985, 420-444.

Dudai, Y., Karni, A., and Born, J. (2015). The consolidation and transformation of memory. Neuron 88, 20-32. doi: 10.1016/j.neuron.2015.09.004

Dulcis, D., Jamshidi, P., Leutgeb, S., and Spitzer, N. C. (2013). Neurotransmitter switching in the adult brain regulates behavior. Science 340, 449-453. doi: $10.1126 /$ science. 1234152

Duman, R. S., and Aghajanian, G. K. (2012). Synaptic dysfunction in depression: potential therapeutic targets. Science 338, 68-72. doi: 10.1126/science.1222939

Duric, V., Banasr, M., Stockmeier, C. A., Simen, A. A., Newton, S. S., Overholser, J. C., et al. (2013). Altered expression of synapse and glutamate related genes in post-mortem hippocampus of depressed subjects. Int. J. Neuropsychopharmacol. 16, 69-82. doi: 10.1017/\$146114571 2000016

Egervari, G., Landry, J., Callens, J., Fullard, J. F., Roussos, P., Keller, E., et al. (2017). Striatal H3K27 acetylation linked to glutamatergic gene dysregulation in human heroin abusers holds promise as therapeutic target. Biol. Psychiatry 81, 585-594. doi: 10.1016/j.biopsych.2016.09.015

Enwright, J. F., Sanapala, S., Foglio, A., Berry, R., Fish, K. N., and Lewis, D. A. (2016). Reduced labeling of parvalbumin neurons and perineuronal nets in the dorsolateral prefrontal cortex of subjects with schizophrenia. Neuropsychopharmacology 41, 2206-2214. doi: 10.1038/npp.2016.24

Euston, D. R., Tatsuno, M., and McNaughton, B. L. (2007). Fast-forward playback of recent memory sequences in prefrontal cortex during sleep. Science 318, 1147-1150. doi: 10.1126/science.1148979

Fanous, A. H., Zhou, B., Aggen, S. H., Bergen, S. E., Amdur, R. L., Duan, J., et al. (2012). Genome-wide association study of clinical dimensions of schizophrenia: polygenic effect on disorganized symptoms. Am. J. Psychiatry 169, 1309-1317. doi: 10.1176/appi.ajp.2012.12020218

Favuzzi, E., Marques-Smith, A., Deogracias, R., Winterflood, C. M., SanchezAguilera, A., Mantoan, L., et al. (2017). Activity-dependent gating of parvalbumin interneuron function by the perineuronal net protein brevican. Neuron 95, 639-655.e610. doi: 10.1016/j.neuron.2017.06.028

Feld, G. B., Besedovsky, L., Kaida, K., Munte, T. F., and Born, J. (2014). Dopamine D2-like receptor activation wipes out preferential consolidation of high over low reward memories during human sleep. J. Cogn. Neurosci. 26, 2310-2320. doi: 10.1162/jocn_a_00629

Fernandez, L. M., Vantomme, G., Osorio-Forero, A., Cardis, R., Beard, E., and Luthi, A. (2018). Thalamic reticular control of local sleep in mouse sensory cortex. Elife 7:39111. doi: 10.7554/eLife.39111

Ferrarelli, F. (2015). Sleep in patients with schizophrenia. Curr. Sleep Med. Rep. 1, 150-156. doi: 10.1007/s40675-015-0010-3

Ferrarelli, F. (2020). Sleep disturbances in schizophrenia and psychosis. Schizophr. Res. 221, 1-3. doi: 10.1016/j.schres.2020.05.022 
Ferrarelli, F., and Tononi, G. (2017). Reduced sleep spindle activity point to a TRNMD thalamus-PFC circuit dysfunction in schizophrenia. Schizophr. Res. 180, 36-43. doi: 10.1016/j.schres.2016.05.023

Ferrarelli, F., Huber, R., Peterson, M. J., Massimini, M., Murphy, M., Riedner, B. A., et al. (2007). Reduced sleep spindle activity in schizophrenia patients. Am. J. Psychiatry 164, 483-492. doi: 10.1176/ajp.2007.164.3.483

Ferreira, M. A., O’Donovan, M. C., Meng, Y. A., Jones, I. R., Ruderfer, D. M., Jones, L., et al. (2008). Collaborative genome-wide association analysis supports a role for ANK3 and CACNA1C in bipolar disorder. Nat. Genet. 40, 1056-1058. doi: $10.1038 / n g .209$

Feyissa, A. M., Chandran, A., Stockmeier, C. A., and Karolewicz, B. (2009). Reduced levels of NR2A and NR2B subunits of NMDA receptor and PSD-95 in the prefrontal cortex in major depression. Prog. Neuropsychopharmacol. Biol. Psychiatry 33, 70-75. doi: 10.1016/j.pnpbp. 2008.10.005

Fiorentino, A., O’Brien, N. L., Locke, D. P., McQuillin, A., Jarram, A., Anjorin, A., et al. (2014). Analysis of ANK3 and CACNA1C variants identified in bipolar disorder whole genome sequence data. Bipolar. Disord. 16, 583-591. doi: $10.1111 /$ bdi. 12203

Fonken, L. K., Frank, M. G., Kitt, M. M., Barrientos, R. M., Watkins, L. R., and Maier, S. F. (2015). Microglia inflammatory responses are controlled by an intrinsic circadian clock. Brain Behav. Immun. 45, 171-179. doi: 10.1016/j.bbi. 2014.11.009

Foscarin, S., Raha-Chowdhury, R., Fawcett, J. W., and Kwok, J. C. F. (2017). Brain ageing changes proteoglycan sulfation, rendering perineuronal nets more inhibitory. Aging (Albany N. Y.) 9, 1607-1622. doi: 10.18632/aging.101256

Frey, U., and Morris, R. G. (1997). Synaptic tagging and long-term potentiation. Nature 385, 533-536. doi: 10.1038/385533a0

Frischknecht, R., and Gundelfinger, E. D. (2012). The brain's extracellular matrix and its role in synaptic plasticity. Adv. Exp. Med. Biol. 970, 153-171. doi: 10.1007/978-3-7091-0932-8_7

Frischknecht, R., Heine, M., Perrais, D., Seidenbecher, C. I., Choquet, D., and Gundelfinger, E. D. (2009). Brain extracellular matrix affects AMPA receptor lateral mobility and short-term synaptic plasticity. Nat. Neurosci. 12, 897-904. doi: $10.1038 / \mathrm{nn} .2338$

Frodl, T., Meisenzahl, E., Zetzsche, T., Bottlender, R., Born, C., Groll, C., et al. (2002). Enlargement of the amygdala in patients with a first episode of major depression. Biol. Psychiatry 51, 708-714.

Fu, J., Li, P., Ouyang, X., Gu, C., Song, Z., Gao, J., et al. (2007). Rapid eye movement sleep deprivation selectively impairs recall of fear extinction in hippocampus-independent tasks in rats. Neuroscience 144, 1186-1192. doi: 10. 1016/j.neuroscience.2006.10.050

Ganguly, K., Rejmak, E., Mikosz, M., Nikolaev, E., Knapska, E., and Kaczmarek, L. (2013). Matrix metalloproteinase (MMP) 9 transcription in mouse brain induced by fear learning. J. Biol. Chem. 288, 20978-20991. doi: 10.1074/jbc. M113.457903

Garey, L. J., Ong, W. Y., Patel, T. S., Kanani, M., Davis, A., Mortimer, A. M., et al. (1998). Reduced dendritic spine density on cerebral cortical pyramidal neurons in schizophrenia. J. Neurol. Neurosurg. Psychiatry 65, 446-453. doi: 10.1136/jnnp.65.4.446

Garwood, J., Heck, N., Reichardt, F., and Faissner, A. (2003). Phosphacan short isoform, a novel non-proteoglycan variant of phosphacan/receptor protein tyrosine phosphatase-beta, interacts with neuronal receptors and promotes neurite outgrowth. J. Biol. Chem. 278, 24164-24173. doi: 10.1074/jbc. M211721200

Geissler, M., Gottschling, C., Aguado, A., Rauch, U., Wetzel, C. H., Hatt, H., et al. (2013). Primary hippocampal neurons, which lack four crucial extracellular matrix molecules, display abnormalities of synaptic structure and function and severe deficits in perineuronal net formation. J. Neurosci. 33, 7742-7755. doi: 10.1523/JNEUROSCI.3275-12.2013

Gerstenberg, M., Furrer, M., Tesler, N., Franscini, M., Walitza, S., and Huber, R. (2020). Reduced sleep spindle density in adolescent patients with early-onset schizophrenia compared to major depressive disorder and healthy controls. Schizophr. Res. 221, 20-28. doi: 10.1016/j.schres.2019.11.060

Gilestro, G. F., Tononi, G., and Cirelli, C. (2009). Widespread changes in synaptic markers as a function of sleep and wakefulness in Drosophila. Science 324, 109-112. doi: 10.1126/science.1166673
Gisabella, B., Farah, S., Peng, X., Burgos-Robles, A., Lim, S. H., and Goosens, K. A. (2016). Growth hormone biases amygdala network activation after fear learning. Transl. Psychiatry 6:e960. doi: 10.1038/tp.2016.203

Gisabella, B., Scammell, T., Bandaru, S. S., and Saper, C. B. (2020). Regulation of hippocampal dendritic spines following sleep deprivation. J. Comp. Neurol. 528, 380-388. doi: 10.1002/cne.24764

Glantz, L. A., and Lewis, D. A. (2000). Decreased dendritic spine density on prefrontal cortical pyramidal neurons in schizophrenia. Arch. Gen. Psychiatry 57, 65-73. doi: 10.1001/archpsyc.57.1.65

Glausier, J. R., and Lewis, D. A. (2013). Dendritic spine pathology in schizophrenia. Neuroscience 251, 90-107. doi: 10.1016/j.neuroscience.2012.04.044

Gogolla, N., Caroni, P., Luthi, A., and Herry, C. (2009). Perineuronal nets protect fear memories from erasure. Science 325, 1258-1261. doi: 10.1126/science. 1174146

Golgi, C. (1989). On the structure of nerve cells. 1898. J. Microsc. 155(Pt 1), 3-7. doi: 10.1111/j.1365-2818.1989.tb04294.x

Gomperts, S. N., Kloosterman, F., and Wilson, M. A. (2015). VTA neurons coordinate with the hippocampal reactivation of spatial experience. Elife 4:5360. doi: 10.7554/eLife.05360

Gottschling, C., Wegrzyn, D., Denecke, B., and Faissner, A. (2019). Elimination of the four extracellular matrix molecules tenascin-C, tenascin-R, brevican and neurocan alters the ratio of excitatory and inhibitory synapses. Sci. Rep. 9:13939. doi: 10.1038/s41598-019-50404-9

Green, C. B., Durston, A. J., and Morgan, R. (2001). The circadian gene Clock is restricted to the anterior neural plate early in development and is regulated by the neural inducer noggin and the transcription factor Otx2. Mech. Dev. 101, 105-110. doi: 10.1016/s0925-4773(00)00559-1

Guazzelli, M., Feinberg, I., Aminoff, M., Fein, G., Floyd, T. C., and Maggini, C. (1986). Sleep spindles in normal elderly: comparison with young adult patterns and relation to nocturnal awakening, cognitive function and brain atrophy. Electroencephalogr. Clin. Neurophysiol. 63, 526-539. doi: 10.1016/ 0013-4694(86)90140-9

Guirado, R., Perez-Rando, M., Sanchez-Matarredona, D., Castren, E., and Nacher, J. (2014). Chronic fluoxetine treatment alters the structure, connectivity and plasticity of cortical interneurons. Int. J. Neuropsychopharmacol. 17, 1635-1646. doi: $10.1017 / S 1461145714000406$

Harb, G. C., Thompson, R., Ross, R. J., and Cook, J. M. (2012). Combat-related PTSD nightmares and imagery rehearsal: nightmare characteristics and relation to treatment outcome. J. Trauma Stress 25, 511-518. doi: 10.1002/jts.21748

Harkness, J. H., Bushana, P. N., Todd, R. P., Clegern, W. C., Sorg, B. A., and Wisor, J. P. (2019). Sleep disruption elevates oxidative stress in parvalbumin-positive cells of the rat cerebral cortex. Sleep 42:201. doi: 10.1093/sleep/zsy201

Harkness, J. H., Gonzalez, A. E., Bushana, P. N., Jorgensen, E. T., Hegarty, D. M., Di Nardo, A. A., et al. (2020). Diurnal changes in perineuronal nets and parvalbumin neurons in the rat medial prefrontal cortex. bioRxiv [Preprint]. doi: 10.1101/2020.10.25.354134

Harper, D. G., Volicer, L., Stopa, E. G., McKee, A. C., Nitta, M., and Satlin, A. (2005). Disturbance of endogenous circadian rhythm in aging and Alzheimer disease. Am. J. Geriatr. Psychiatry 13, 359-368. doi: 10.1176/appi.ajgp.13.5.359

Harvey, A. G., Schmidt, D. A., Scarna, A., Semler, C. N., and Goodwin, G. M. (2005). Sleep-related functioning in euthymic patients with bipolar disorder, patients with insomnia, and subjects without sleep problems. Am. J. Psychiatry 162, 50-57. doi: 10.1176/appi.ajp.162.1.50

Havekes, R., and Aton, S. J. (2020). Impacts of sleep loss versus waking experience on brain plasticity: parallel or orthogonal? Trends Neurosci. 43, 385-393. doi: 10.1016/j.tins.2020.03.010

Havekes, R., Park, A. J., Tudor, J. C., Luczak, V. G., Hansen, R. T., Ferri, S. L., et al. (2016). Sleep deprivation causes memory deficits by negatively impacting neuronal connectivity in hippocampal area CA1. Elife 5:13424. doi: 10.7554/ eLife. 13424

Hayashi, N., Tatsumi, K., Okuda, H., Yoshikawa, M., Ishizaka, S., Miyata, S., et al. (2007). DACS, novel matrix structure composed of chondroitin sulfate proteoglycan in the brain. Biochem. Biophys. Res. Commun. 364, 410-415. doi: 10.1016/j.bbrc.2007.10.040

Hayashi, Y., Koyanagi, S., Kusunose, N., Okada, R., Wu, Z., Tozaki-Saitoh, H., et al. (2013a). The intrinsic microglial molecular clock controls synaptic strength via the circadian expression of cathepsin S. Sci. Rep. 3:2744. doi: 10.1038/srep02744 
Hayashi, Y., Koyanagi, S., Kusunose, N., Takayama, F., Okada, R., Wu, Z., et al. (2013b). Diurnal spatial rearrangement of microglial processes through the rhythmic expression of P2Y12 receptors. Neurol. Disord. 1, 1-7.

Henderson, F., Vialou, V., El Mestikawy, S., and Fabre, V. (2017). Effects of social defeat stress on sleep in mice. Front. Behav. Neurosci. 11:227. doi: 10.3389/ fnbeh.2017.00227

Henriksen, T. E. G., Gronli, J., Assmus, J., Fasmer, O. B., Schoeyen, H., Leskauskaite, I., et al. (2020). Blue-blocking glasses as additive treatment for mania: effects on actigraphy-derived sleep parameters. J. Sleep Res. 29:e12984. doi: $10.1111 /$ jsr.12984

Henriksen, T. E., Skrede, S., Fasmer, O. B., Hamre, B., Gronli, J., and Lund, A. (2014). Blocking blue light during mania - markedly increased regularity of sleep and rapid improvement of symptoms: a case report. Bipolar. Disord. 16, 894-898. doi: 10.1111/bdi.12265

Henriksen, T. E., Skrede, S., Fasmer, O. B., Schoeyen, H., Leskauskaite, I., BjorkeBertheussen, J., et al. (2016). Blue-blocking glasses as additive treatment for mania: a randomized placebo-controlled trial. Bipolar. Disord. 18, 221-232. doi: $10.1111 /$ bdi. 12390

Hobohm, C., Gunther, A., Grosche, J., Rossner, S., Schneider, D., and Bruckner, G. (2005). Decomposition and long-lasting downregulation of extracellular matrix in perineuronal nets induced by focal cerebral ischemia in rats. J. Neurosci. Res. 80, 539-548. doi: 10.1002/jnr.20459

Hoekman, M. F., Jacobs, F. M., Smidt, M. P., and Burbach, J. P. (2006). Spatial and temporal expression of FoxO transcription factors in the developing and adult murine brain. Gene Expr. Patt. 6, 134-140. doi: 10.1016/j.modgep.2005.07.003

Hofman, M. A., Zhou, J. N., and Swaab, D. F. (1996). Suprachiasmatic nucleus of the human brain: an immunocytochemical and morphometric analysis. Anat. Rec. 244, 552-562. doi: 10.1002/(SICI)1097-0185(199604)244:4<552:: AID-AR13<3.0.CO;2-O

Horii-Hayashi, N., Tatsumi, K., Matsusue, Y., Okuda, H., Okuda, A., Hayashi, M., et al. (2010). Chondroitin sulfate demarcates astrocytic territories in the mammalian cerebral cortex. Neurosci. Lett. 483, 67-72. doi: 10.1016/j.neulet. 2010.07.064

Huang, Y. L., Liu, R. Y., Wang, Q. S., Van Someren, E. J., Xu, H., and Zhou, J. N. (2002). Age-associated difference in circadian sleep-wake and rest-activity rhythms. Physiol. Behav. 76, 597-603. doi: 10.1016/s0031-9384(02)00733-3

Hyman, S. E., and Malenka, R. C. (2001). Addiction and the brain: the neurobiology of compulsion and its persistence. Nat. Rev. Neurosci. 2, 695-703. doi: 10.1038/ 35094560

Inostroza, M., and Born, J. (2013). Sleep for preserving and transforming episodic memory. Annu. Rev. Neurosci. 36, 79-102. doi: 10.1146/annurev-neuro062012-170429

Jackson, A., Cavanagh, J., and Scott, J. (2003). A systematic review of manic and depressive prodromes. J. Affect. Disord. 74, 209-217. doi: 10.1016/s01650327(02)00266-5

Jacobs, F. M., van der Heide, L. P., Wijchers, P. J., Burbach, J. P., Hoekman, M. F., and Smidt, M. P. (2003). FoxO6, a novel member of the FoxO class of transcription factors with distinct shuttling dynamics. J. Biol. Chem. 278, 35959-35967. doi: 10.1074/jbc.M302804200

Jenkins, J. G., and Dellenbach, K. M. (1924). Obliviscence during sleep and waking. Am. J. Psychol. 35, 605-612.

Johansson, A. S., Brask, J., Owe-Larsson, B., Hetta, J., and Lundkvist, G. B. (2011). Valproic acid phase shifts the rhythmic expression of Period2::Luciferase. J. Biol. Rhythms 26, 541-551. doi: 10.1177/0748730411419775

Jones, J. R., Simon, T., Lones, L., and Herzog, E. D. (2018). SCN VIP neurons are essential for normal light-mediated resetting of the circadian system. J. Neurosci. 38, 7986-7995. doi: 10.1523/JNEUROSCI.1322-18.2018

Ju, Y. E., McLeland, J. S., Toedebusch, C. D., Xiong, C., Fagan, A. M., Duntley, S. P., et al. (2013). Sleep quality and preclinical Alzheimer disease. JAMA Neurol. 70, 587-593. doi: 10.1001/jamaneurol.2013.2334

Kaladchibachi, S., and Fernandez, F. (2018). Precision light for the treatment of psychiatric disorders. Neural Plast. 2018:5868570. doi: 10.1155/2018/5 868570

Kalb, R. G., and Hockfield, S. (1988). Molecular evidence for early activitydependent development of hamster motor neurons. J. Neurosci. 8, 2350-2360.

Kang, H. J., Voleti, B., Hajszan, T., Rajkowska, G., Stockmeier, C. A., Licznerski, P., et al. (2012). Decreased expression of synapse-related genes and loss of synapses in major depressive disorder. Nat. Med. 18, 1413-1417. doi: 10.1038/nm.2886
Karolewicz, B., Szebeni, K., Gilmore, T., Maciag, D., Stockmeier, C. A., and Ordway, G. A. (2009). Elevated levels of NR2A and PSD-95 in the lateral amygdala in depression. Int. J. Neuropsychopharmacol. 12, 143-153. doi: 10. 1017/S1461145708008985

Katsuki, F., McNally, J. M., Thankachan, S., McKenna, J. T., Brown, R. E., Strecker, R. E., et al. (2017). Optogenetic manipulation of parvalbumin containing GABAergic neurons in the thalamic reticular nucleus alters declarative and non-declarative memories in mice. SLEEP 40(Suppl. 1), A80-A81.

Keeney, A. J., Hogg, S., and Marsden, C. A. (2001). Alterations in core body temperature, locomotor activity, and corticosterone following acute and repeated social defeat of male NMRI mice. Physiol. Behav. 74, 177-184. doi: 10.1016/s0031-9384(01)00541-8

Kim, H. J., Cho, M. H., Shim, W. H., Kim, J. K., Jeon, E. Y., Kim, D. H., et al. (2017). Deficient autophagy in microglia impairs synaptic pruning and causes social behavioral defects. Mol. Psychiatry 22, 1576-1584. doi: 10.1038/mp.2016.103

Klemfuss, H. (1992). Rhythms and the pharmacology of lithium. Pharmacol. Ther. $56,53-78$.

Knoblauch, V., Munch, M., Blatter, K., Martens, W. L., Schroder, C., Schnitzler, C., et al. (2005). Age-related changes in the circadian modulation of sleep-spindle frequency during nap sleep. Sleep 28, 1093-1101. doi: 10.1093/sleep/28.9.1093

Konopaske, G. T., Lange, N., Coyle, J. T., and Benes, F. M. (2014). Prefrontal cortical dendritic spine pathology in schizophrenia and bipolar disorder. JAMA Psychiatry 71, 1323-1331. doi: 10.1001/jamapsychiatry.2014.1582

Konopaske, G. T., Subburaju, S., Coyle, J. T., and Benes, F. M. (2015). Altered prefrontal cortical MARCKS and PPP1R9A mRNA expression in schizophrenia and bipolar disorder. Schizophr. Res. 164, 100-108. doi: 10.1016/j.schres.2015. 02.005

Koob, G. F., and Colrain, I. M. (2020). Alcohol use disorder and sleep disturbances: a feed-forward allostatic framework. Neuropsychopharmacology 45, 141-165. doi: 10.1038/s41386-019-0446-0

Koskinen, M. K., van Mourik, Y., Smit, A. B., Riga, D., and Spijker, S. (2020). From stress to depression: development of extracellular matrix-dependent cognitive impairment following social stress. Sci. Rep. 10:17308. doi: 10.1038/s41598-02073173-2

Kovatsi, L., Batzios, S., Nikolaou, K., Fragou, D., Njau, S., Tsatsakis, A., et al. (2013). Alterations in serum MMP and TIMP concentrations following chronic heroin abuse. Toxicol. Mech. Methods 23, 377-381. doi: 10.3109/15376516.2012. 758681

Kristiansen, L. V., Bakir, B., Haroutunian, V., and Meador-Woodruff, J. H. (2010). Expression of the NR2B-NMDA receptor trafficking complex in prefrontal cortex from a group of elderly patients with schizophrenia. Schizophr. Res. 119, 198-209. doi: 10.1016/j.schres.2010.02.1069

Kudrimoti, H. S., Barnes, C. A., and McNaughton, B. L. (1999). Reactivation of hippocampal cell assemblies: effects of behavioral state, experience, and EEG dynamics. J. Neurosci. 19, 4090-4101.

Kumar, D., Dedic, C., Flachskamm, J., Deussing, J., and Kimura, M. (2013). CAV1.2 calcium channel is involved in the circadian regulation of sleep. Sleep Med. 14(Suppl. 1):e175.

Kuriyama, K., Soshi, T., and Kim, Y. (2010). Sleep deprivation facilitates extinction of implicit fear generalization and physiological response to fear. Biol. Psychiatry 68, 991-998. doi: 10.1016/j.biopsych.2010.08.015

Landgraf, D., Long, J. E., Proulx, C. D., Barandas, R., Malinow, R., and Welsh, D. K. (2016). Genetic disruption of circadian rhythms in the suprachiasmatic nucleus causes helplessness, behavioral despair, and anxiety-like behavior in mice. Biol. Psychiatry 80, 827-835.

Lange, C., and Irle, E. (2004). Enlarged amygdala volume and reduced hippocampal volume in young women with major depression. Psychol. Med. 34, 1059-1064.

Lansink, C. S., Goltstein, P. M., Lankelma, J. V., McNaughton, B. L., and Pennartz, C. M. (2009). Hippocampus leads ventral striatum in replay of place-reward information. PLoS Biol. 7:e1000173. doi: 10.1371/journal.pbio.1000173

Laruelle, M., Abi-Dargham, A., Gil, R., Kegeles, L., and Innis, R. (1999). Increased dopamine transmission in schizophrenia: relationship to illness phases. Biol. Psychiatry 46, 56-72. doi: 10.1016/s0006-3223(99)00067-0

Lasek, A. W., Chen, H., and Chen, W. Y. (2018). Releasing addiction memories trapped in perineuronal nets. Trends Genet. 34, 197-208. doi: 10.1016/j.tig.2017. 12.004

Latchoumane, C. V., Ngo, H. V., Born, J., and Shin, H. S. (2017). Thalamic spindles promote memory formation during sleep through triple phase-locking 
of cortical, thalamic, and hippocampal rhythms. Neuron 95, 424-435.e426. doi: 10.1016/j.neuron.2017.06.025

Leibenluft, E., Albert, P. S., Rosenthal, N. E., and Wehr, T. A. (1996). Relationship between sleep and mood in patients with rapid-cycling bipolar disorder. Psychiatry Res. 63, 161-168. doi: 10.1016/0165-1781(96)02854-5

Lendvai, D., Morawski, M., Bruckner, G., Negyessy, L., Baksa, G., Glasz, T., et al. (2012). Perisynaptic aggrecan-based extracellular matrix coats in the human lateral geniculate body devoid of perineuronal nets. J. Neurosci. Res. 90, 376-387. doi: 10.1002/jnr.22761

Lendvai, D., Morawski, M., Negyessy, L., Gati, G., Jager, C., Baksa, G., et al. (2013). Neurochemical mapping of the human hippocampus reveals perisynaptic matrix around functional synapses in Alzheimer's disease. Acta Neuropathol. 125, 215-229. doi: 10.1007/s00401-012-1042-0

Li, J. Z., Bunney, B. G., Meng, F., Hagenauer, M. H., Walsh, D. M., Vawter, M. P., et al. (2013). Circadian patterns of gene expression in the human brain and disruption in major depressive disorder. Proc. Natl. Acad. Sci. U.S.A. 110, 9950-9955. doi: 10.1073/pnas.1305814110

Li, J., Lu, W. Q., Beesley, S., Loudon, A. S., and Meng, Q. J. (2012). Lithium impacts on the amplitude and period of the molecular circadian clockwork. PLoS One 7:e33292. doi: 10.1371/journal.pone.0033292

Li, W., Ma, L., Yang, G., and Gan, W. B. (2017). REM sleep selectively prunes and maintains new synapses in development and learning. Nat. Neurosci. 20, 427-437. doi: 10.1038/nn.4479

Licznerski, P., and Duman, R. S. (2013). Remodeling of axo-spinous synapses in the pathophysiology and treatment of depression. Neuroscience 251, 33-50. doi: 10.1016/j.neuroscience.2012.09.057

Lin, J. S., Gervasoni, D., Hou, Y., Vanni-Mercier, G., Rambert, F., Frydman, A., et al. (2000). Effects of amphetamine and modafinil on the sleep/wake cycle during experimental hypersomnia induced by sleep deprivation in the cat. J. Sleep Res. 9, 89-96. doi: 10.1046/j.1365-2869.2000.00181.x

Lin, R., Rosahl, T. W., Whiting, P. J., Fawcett, J. W., and Kwok, J. C. (2011). 6Sulphated chondroitins have a positive influence on axonal regeneration. PLoS One 6:e21499. doi: 10.1371/journal.pone.0021499

Liu, Y., Blackwood, D. H., Caesar, S., de Geus, E. J., Farmer, A., Ferreira, M. A., et al. (2011). Meta-analysis of genome-wide association data of bipolar disorder and major depressive disorder. Mol. Psychiatry 16, 2-4. doi: 10.1038/mp.2009.107

MacDonald, M. L., Alhassan, J., Newman, J. T., Richard, M., Gu, H., Kelly, R. M., et al. (2017). Selective loss of smaller spines in schizophrenia. Am. J. Psychiatry 174, 586-594. doi: 10.1176/appi.ajp.2017.16070814

Maeda, N., Fukazawa, N., and Ishii, M. (2010). Chondroitin sulfate proteoglycans in neural development and plasticity. Front. Biosci. J. Virt. Lib. 15:626-644.

Maeda, N., Ishii, M., Nishimura, K., and Kamimura, K. (2011). Functions of chondroitin sulfate and heparan sulfate in the developing brain. Neurochem. Res. 36, 1228-1240. doi: 10.1007/s11064-010-0324-y

Manoach, D. S., and Stickgold, R. (2019). Abnormal sleep spindles, memory consolidation, and schizophrenia. Annu. Rev. Clin. Psychol. 15, 451-479. doi: 10.1146/annurev-clinpsy-050718-095754

Manoach, D. S., Demanuele, C., Wamsley, E. J., Vangel, M., Montrose, D. M., Miewald, J., et al. (2014). Sleep spindle deficits in antipsychotic-naive early course schizophrenia and in non-psychotic first-degree relatives. Front. Hum. Neurosci. 8:762. doi: 10.3389/fnhum.2014.00762

Manoach, D. S., Pan, J. Q., Purcell, S. M., and Stickgold, R. (2016). Reduced sleep spindles in schizophrenia: a treatable endophenotype that links risk genes to impaired cognition? Biol. Psychiatry 80, 599-608. doi: 10.1016/j.biopsych.2015. 10.003

Manoach, D. S., Thakkar, K. N., Stroynowski, E., Ely, A., McKinley, S. K., Wamsley, E., et al. (2010). Reduced overnight consolidation of procedural learning in chronic medicated schizophrenia is related to specific sleep stages. J. Psychiatr Res. 44, 112-120. doi: 10.1016/j.jpsychires.2009.06.011

Mansour, H. A., Talkowski, M. E., Wood, J., Chowdari, K. V., McClain, L., Prasad, K., et al. (2009). Association study of 21 circadian genes with bipolar I disorder, schizoaffective disorder, and schizophrenia. Bipolar. Disord. 11, 701-710. doi: 10.1111/j.1399-5618.2009.00756.x

Maret, S., Faraguna, U., Nelson, A. B., Cirelli, C., and Tononi, G. (2011). Sleep and waking modulate spine turnover in the adolescent mouse cortex. Nat. Neurosci. 14, 1418-1420. doi: 10.1038/nn.2934

Markovic, A., Buckley, A., Driver, D. I., Dillard-Broadnax, D., Gochman, P. A., Hoedlmoser, K., et al. (2020). Sleep spindle activity in childhood onset schizophrenia: diminished and associated with clinical symptoms. Schizophr. Res. 223, 327-336. doi: 10.1016/j.schres.2020.08.022

Martin, S. J., Grimwood, P. D., and Morris, R. G. (2000). Synaptic plasticity and memory: an evaluation of the hypothesis. Annu. Rev. Neurosci. 23, 649-711. doi: 10.1146/annurev.neuro.23.1.649

Mauney, S. A., Athanas, K. M., Pantazopoulos, H., Shaskan, N., Passeri, E., Berretta, S., et al. (2013). Developmental pattern of perineuronal nets in the human prefrontal cortex and their deficit in schizophrenia. Biol. Psychiatry 74, 427-435. doi: 10.1016/j.biopsych.2013.05.007

Mazuski, C., Abel, J. H., Chen, S. P., Hermanstyne, T. O., Jones, J. R., Simon, T., et al. (2018). Entrainment of circadian rhythms depends on firing rates and neuropeptide release of VIP SCN neurons. Neuron 99, 555-563.e555. doi: 10.1016/j.neuron.2018.06.029

Mazuski, C., Chen, S. P., and Herzog, E. D. (2020). Different roles for VIP neurons in the neonatal and adult suprachiasmatic nucleus. J. Biol. Rhythms 35, 465-475. doi: $10.1177 / 0748730420932073$

McCarthy, M. J., and Welsh, D. K. (2012). Cellular circadian clocks in mood disorders. J. Biol. Rhythms 27, 339-352. doi: 10.1177/0748730412456367

McCarthy, M. J., Le Roux, M. J., Wei, H., Beesley, S., Kelsoe, J. R., and Welsh, D. K. (2016). Calcium channel genes associated with bipolar disorder modulate lithium's amplification of circadian rhythms. Neuropharmacology 101, 439-448. doi: 10.1016/j.neuropharm.2015.10.017

McCarthy, M. J., Nievergelt, C. M., Kelsoe, J. R., and Welsh, D. K. (2012). A survey of genomic studies supports association of circadian clock genes with bipolar disorder spectrum illnesses and lithium response. PLoS One 7:e32091. doi: 10.1371/journal.pone.0032091

McCarthy, M. J., Wei, H., Marnoy, Z., Darvish, R. M., McPhie, D. L., Cohen, B. M., et al. (2013). Genetic and clinical factors predict lithium's effects on PER2 gene expression rhythms in cells from bipolar disorder patients. Transl. Psychiatry 3:e318. doi: 10.1038/tp.2013.90

McCarthy, M. J., Wei, H., Nievergelt, C. M., Stautland, A., Maihofer, A. X., Welsh, D. K., et al. (2019). Chronotype and cellular circadian rhythms predict the clinical response to lithium maintenance treatment in patients with bipolar disorder. Neuropsychopharmacology 44, 620-628. doi: 10.1038/s41386-0180273-8

McClung, C. A. (2013). How might circadian rhythms control mood? let me count the ways. Biol. Psychiatry 74, 242-249. doi: 10.1016/j.biopsych.2013.02.019

McDermott, C. M., Hardy, M. N., Bazan, N. G., and Magee, J. C. (2006). Sleep deprivation-induced alterations in excitatory synaptic transmission in the CA1 region of the rat hippocampus. J. Physiol. 570(Pt 3), 553-565. doi: 10.1113/ jphysiol.2005.093781

McKinney, B. C., MacDonald, M. L., Newman, J. T., Shelton, M. A., DeGiosio, R. A., Kelly, R. M., et al. (2019). Density of small dendritic spines and microtubule-associated-protein-2 immunoreactivity in the primary auditory cortex of subjects with schizophrenia. Neuropsychopharmacology 44, 10551061. doi: 10.1038/s41386-019-0350-7

Medina, A. B., Lechuga, D. A., Escandon, O. S., and Moctezuma, J. V. (2014). Update of sleep alterations in depression. Sleep Sci. 7, 165-169. doi: 10.1016/ j.slsci.2014.09.015

Medina-Flores, R., Wang, G., Bissel, S. J., Murphey-Corb, M., and Wiley, C. A. (2004). Destruction of extracellular matrix proteoglycans is pervasive in simian retroviral neuroinfection. Neurobiol. Dis. 16, 604-616. doi: 10.1016/j.nbd.2004. 04.011

Meerlo, P., De Boer, S. F., Koolhaas, J. M., Daan, S., and Van den Hoofdakker, R. H. (1996). Changes in daily rhythms of body temperature and activity after a single social defeat in rats. Physiol. Behav. 59, 735-739. doi: 10.1016/0031-9384(95) 02182-5

Meerlo, P., Pragt, B. J., and Daan, S. (1997). Social stress induces high intensity sleep in rats. Neurosci. Lett. 225, 41-44. doi: 10.1016/s0304-3940(97)00180-8

Mellman, T. A., Bustamante, V., Fins, A. I., Pigeon, W. R., and Nolan, B. (2002). REM sleep and the early development of posttraumatic stress disorder. Am. J. Psychiatry 159, 1696-1701. doi: 10.1176/appi.ajp.159. 10.1696

Merikanto, I., Utge, S., Lahti, J., Kuula, L., Makkonen, T., Lahti-Pulkkinen, M., et al. (2019). Genetic risk factors for schizophrenia associate with sleep spindle activity in healthy adolescents. J. Sleep Res. 28:e12762. doi: 10.1111/jsr.12762

Meyer, N., Faulkner, S. M., McCutcheon, R. A., Pillinger, T., Dijk, D. J., and MacCabe, J. H. (2020). Sleep and circadian rhythm disturbance in remitted 
schizophrenia and bipolar disorder: a systematic review and meta-analysis. Schizophr. Bull. 46, 1126-1143. doi: 10.1093/schbul/sbaa024

Meyer, R. M., Burgos-Robles, A., Liu, E., Correia, S. S., and Goosens, K. A. (2014). A ghrelin-growth hormone axis drives stress-induced vulnerability to enhanced fear. Mol. Psychiatry 19, 1284-1294. doi: 10.1038/mp.2013.135

Mitlohner, J., Kaushik, R., Niekisch, H., Blondiaux, A., Gee, C. E., Happel, M. F. K., et al. (2020). Dopamine receptor activation modulates the integrity of the perisynaptic extracellular matrix at excitatory synapses. Cells 9:260. doi: 10. 3390/cells9020260

Miyamoto, A., Wake, H., Moorhouse, A. J., and Nabekura, J. (2013). Microglia and synapse interactions: fine tuning neural circuits and candidate molecules. Front. Cell Neurosci. 7:70. doi: 10.3389/fncel.2013.00070

Miyata, S., and Kitagawa, H. (2016). Chondroitin 6-sulfation regulates perineuronal net formation by controlling the stability of aggrecan. Neural. Plast 2016:1305801. doi: 10.1155/2016/1305801

Miyata, S., Komatsu, Y., Yoshimura, Y., Taya, C., and Kitagawa, H. (2012). Persistent cortical plasticity by upregulation of chondroitin 6-sulfation. Nat. Neurosci. 15, S411-S412. doi: 10.1038/nn.3023

Mizoguchi, H., Yamada, K., Mouri, A., Niwa, M., Mizuno, T., Noda, Y., et al. (2007). Role of matrix metalloproteinase and tissue inhibitor of MMP in methamphetamine-induced behavioral sensitization and reward: implications for dopamine receptor down-regulation and dopamine release. J. Neurochem. 102, 1548-1560. doi: 10.1111/j.1471-4159.2007.04623.x

Moravcova, S., Cervena, K., Mikova, H., Pacesova, D., Pallag, G., Novotny, J., et al. (2020). Social defeat stress affects resident's clock gene and bdnf expression in the brain. Stress 20, 1-7. doi: 10.1080/10253890.2020.1759548

Morawski, M., Bruckner, G., Jager, C., Seeger, G., and Arendt, T. (2010). Neurons associated with aggrecan-based perineuronal nets are protected against tau pathology in subcortical regions in Alzheimer's disease. Neuroscience 169, 1347-1363. doi: 10.1016/j.neuroscience.2010.05.022

Morawski, M., Bruckner, M. K., Riederer, P., Bruckner, G., and Arendt, T. (2004). Perineuronal nets potentially protect against oxidative stress. Exp. Neurol. 188, 309-315. doi: 10.1016/j.expneurol.2004.04.017

Morgan, R. (2002). The circadian gene Clock is required for the correct early expression of the head specific gene Otx2. Int. J. Dev. Biol. 46, 999-1004.

Muir, E. M., Adcock, K. H., Morgenstern, D. A., Clayton, R., von Stillfried, N., Rhodes, K., et al. (2002). Matrix metalloproteases and their inhibitors are produced by overlapping populations of activated astrocytes. Brain Res. Mol. Brain Res. 100, 103-117.

Muller, G. E., and Pilzecker, A. (1900). Experimentelle Beitra "ge zur Lehre vom Geda "chtnis. Z. Psychol. Erganzungsband 1, 1-300.

Murray, G. (2007). Diurnal mood variation in depression: a signal of disturbed circadian function? J. Affect. Disord. 102, 47-53. doi: 10.1016/j.jad.2006.12.001

Murray, G. (2008). Major depressive disorder: afternoon and evening diurnal mood variation is common. Evid. Based Ment. Health 11:59. doi: 10.1136/ebmh.11.2. 59

Murray, G., Allen, N. B., and Trinder, J. (2002). Mood and the circadian system: investigation of a circadian component in positive affect. Chronobiol. Int. 19, 1151-1169.

Murray, G., Nicholas, C. L., Kleiman, J., Dwyer, R., Carrington, M. J., Allen, N. B., et al. (2009). Nature's clocks and human mood: the circadian system modulates reward motivation. Emotion 9, 705-716. doi: 10.1037/a0017080

Musiek, E. S., Bhimasani, M., Zangrilli, M. A., Morris, J. C., Holtzman, D. M., and Ju, Y. S. (2018). Circadian rest-activity pattern changes in aging and preclinical Alzheimer disease. JAMA Neurol. 75, 582-590. doi: 10.1001/jamaneurol.2017. 4719

Nagy, V., Bozdagi, O., and Huntley, G. W. (2007). The extracellular protease matrix metalloproteinase- 9 is activated by inhibitory avoidance learning and required for long-term memory. Learn. Mem. 14, 655-664. doi: 10.1101/lm.678307

Nagy, V., Bozdagi, O., Matynia, A., Balcerzyk, M., Okulski, P., Dzwonek, J., et al. (2006). Matrix metalloproteinase-9 is required for hippocampal late-phase long-term potentiation and memory. J. Neurosci. 26, 1923-1934. doi: 10.1523/ JNEUROSCI.4359-05.2006

Narishige, S., Kuwahara, M., Shinozaki, A., Okada, S., Ikeda, Y., Kamagata, M., et al. (2014). Effects of caffeine on circadian phase, amplitude and period evaluated in cells in vitro and peripheral organs in vivo in PER2::LUCIFERASE mice. $\mathrm{Br}$. J. Pharmacol. 171, 5858-5869. doi: 10.1111/bph. 12890
Natarajan, R., Harding, J. W., and Wright, J. W. (2013). A role for matrix metalloproteinases in nicotine-induced conditioned place preference and relapse in adolescent female rats. J. Exp. Neurosci. 7, 1-14. doi: 10.4137/JEN. S11381

Nguyen, P. T., Dorman, L. C., Pan, S., Vainchtein, I. D., Han, R. T., Nakao-Inoue, H., et al. (2020). Microglial remodeling of the extracellular matrix promotes synapse plasticity. Cell 182, 388-403.e315. doi: 10.1016/j.cell.2020.05.050

Niethard, N., Hasegawa, M., Itokazu, T., Oyanedel, C. N., Born, J., and Sato, T. R. (2016). Sleep-Stage-specific regulation of cortical excitation and inhibition. Curr. Biol. 26, 2739-2749. doi: 10.1016/j.cub.2016.08.035

Nievergelt, C. M., Kripke, D. F., Barrett, T. B., Burg, E., Remick, R. A., Sadovnick, A. D., et al. (2006). Suggestive evidence for association of the circadian genes PERIOD3 and ARNTL with bipolar disorder. Am. J. Med. Genet. B Neuropsychiatr. Genet. 141B, 234-241. doi: 10.1002/ajmg.b.30252

Nikolaienko, O., Patil, S., Eriksen, M. S., and Bramham, C. R. (2018). Arc protein: a flexible hub for synaptic plasticity and cognition. Semin. Cell. Dev. Biol. 77, 33-42. doi: 10.1016/j.semcdb.2017.09.006

Noguchi, T., Lo, K., Diemer, T., and Welsh, D. K. (2016). Lithium effects on circadian rhythms in fibroblasts and suprachiasmatic nucleus slices from Cry knockout mice. Neurosci. Lett. 619, 49-53. doi: 10.1016/j.neulet.2016.02.030

Nudell, V., Wei, H., Nievergelt, C., Maihofer, A. X., Shilling, P., Alda, M., et al. (2019). Entrainment of circadian rhythms to temperature reveals amplitude deficits in fibroblasts from patients with bipolar disorder and possible links to calcium channels. Mol. Neuropsychiatry 5, 115-124. doi: 10.1159/000497354

Ognjanovski, N., Schaeffer, S., Wu, J., Mofakham, S., Maruyama, D., Zochowski, M., et al. (2017). Parvalbumin-expressing interneurons coordinate hippocampal network dynamics required for memory consolidation. Nat. Commun. 8:15039. doi: 10.1038/ncomms15039

Ota, S. M., Hut, R. A., Riede, S. J., Crosby, P., Suchecki, D., and Meerlo, P. (2020). Social stress and glucocorticoids alter PERIOD2 rhythmicity in the liver, but not in the suprachiasmatic nucleus. Horm. Behav. 120:104683. doi: 10.1016/j.yhbeh. 2020.104683

Ota, S. M., Suchecki, D., and Meerlo, P. (2018). Chronic social defeat stress suppresses locomotor activity but does not affect the free-running circadian period of the activity rhythm in mice. Neurobiol. Sleep Circad. Rhythms 5, 1-7. doi: 10.1016/j.nbscr.2018.03.002

Pagani, L., St Clair, P. A., Teshiba, T. M., Service, S. K., Fears, S. C., Araya, C., et al. (2016). Genetic contributions to circadian activity rhythm and sleep pattern phenotypes in pedigrees segregating for severe bipolar disorder. Proc. Natl. Acad. Sci. U.S.A. 113, E754-E761. doi: 10.1073/pnas.1513525113

Palagini, L., Baglioni, C., Ciapparelli, A., Gemignani, A., and Riemann, D. (2013). REM sleep dysregulation in depression: state of the art. Sleep Med. Rev. 17, 377-390. doi: 10.1016/j.smrv.2012.11.001

Pandey, A., Davis, N. A., White, B. C., Pajewski, N. M., Savitz, J., Drevets, W. C., et al. (2012). Epistasis network centrality analysis yields pathway replication across two GWAS cohorts for bipolar disorder. Transl. Psychiatry 2:e154. doi: $10.1038 /$ tp. 2012.80

Pantazopoulos, H., Dolatshad, H., and Davis, F. C. (2010a). Chronic stimulation of the hypothalamic vasoactive intestinal peptide receptor lengthens circadian period in mice and hamsters. Am. J. Physiol. Regul. Integr. Comp. Physiol. 299, R379-R385. doi: 10.1152/ajpregu.00176.2010

Pantazopoulos, H., Gamble, K., Stork, O., and Amir, S. (2018). Circadian rhythms in regulation of brain processes and role in psychiatric disorders. Neural. Plast. 2018:5892657. doi: 10.1155/2018/5892657

Pantazopoulos, H., Gisabella, B., Rexrode, L., Benefield, D., Yildiz, E., Seltzer, P., et al. (2020a). Circadian rhythms of perineuronal net composition. eNeuro 7:1523. doi: 10.1523/ENEURO.0034-19.2020

Pantazopoulos, H., Katsel, P., Haroutunian, V., Chelini, G., Klengel, T., and Berretta, S. (2020b). Molecular signature of extracellular matrix pathology in schizophrenia. Eur. J. Neurosci. doi: 10.1111/ejn.15009 [Epub ahead of print].

Pantazopoulos, H., Markota, M., Jaquet, F., Ghosh, D., Wallin, A., Santos, A., et al. (2015). Aggrecan and chondroitin-6-sulfate abnormalities in schizophrenia and bipolar disorder: a postmortem study on the amygdala. Transl. Psychiatry 5:e496. doi: 10.1038/tp.2014.128

Pantazopoulos, H., Sawyer, C., Heckers, S., Berretta, S., and Markota, M. (2014). Chondroitin sulfate proteoglycan abnormalities in the hippocampus of subjects with schizophrenia. Neuropsychopharmacology 39, S298-S299. 
Pantazopoulos, H., Wiseman, J. T., Markota, M., Ehrenfeld, L., and Berretta, S. (2016). Decreased numbers of somatostatin-expressing neurons in the amygdala of subjects with bipolar disorder or schizophrenia: relationship to circadian rhythms. Biol. Psychiatry 81, 536-547. doi: 10.1016/j.biopsych.2016. 04.006

Pantazopoulos, H., Wiseman, J. T., Markota, M., Ehrenfeld, L., and Berretta, S. (2017). Decreased numbers of somatostatin-expressing neurons in the amygdala of subjects with bipolar disorder or schizophrenia: relationship to circadian rhythms. Biol. Psychiatry 81, 536-547. doi: 10.1016/j.biopsych.2016. 04.006

Pantazopoulos, H., Woo, T. U., Lim, M. P., Lange, N., and Berretta, S. (2010b). Extracellular matrix-glial abnormalities in the amygdala and entorhinal cortex of subjects diagnosed with schizophrenia. Arch. Gen. Psychiatry 67, 155-166. doi: 10.1001/archgenpsychiatry.2009.196

Paolicelli, R. C., Bolasco, G., Pagani, F., Maggi, L., Scianni, M., Panzanelli, P., et al. (2011). Synaptic pruning by microglia is necessary for normal brain development. Science 333, 1456-1458. doi: 10.1126/science.1202529

Parker, E. M., and Sweet, R. A. (2017). Stereological assessments of neuronal pathology in auditory cortex in schizophrenia. Front. Neuroanat. 11:131. doi: 10.3389/fnana.2017.00131

Parsons, R. G., and Ressler, K. J. (2013). Implications of memory modulation for post-traumatic stress and fear disorders. Nat. Neurosci. 16, 146-153. doi: 10.1038/nn.3296

Pasch, K. E., Latimer, L. A., Cance, J. D., Moe, S. G., and Lytle, L. A. (2012). Longitudinal bi-directional relationships between sleep and youth substance use. J. Youth Adolesc. 41, 1184-1196. doi: 10.1007/s10964-012-9784-5

Pavlides, C., and Winson, J. (1989). Influences of hippocampal place cell firing in the awake state on the activity of these cells during subsequent sleep episodes. J. Neurosci. 9, 2907-2918.

Penzes, P., Cahill, M. E., Jones, K. A., VanLeeuwen, J. E., and Woolfrey, K. M. (2011). Dendritic spine pathology in neuropsychiatric disorders. Nat. Neurosci. 14, 285-293. doi: 10.1038/nn.2741

Petanceska, S., Canoll, P., and Devi, L. A. (1996). Expression of rat cathepsin S in phagocytic cells. J. Biol. Chem. 271, 4403-4409.

Pizzagalli, D. A., Berretta, S., Wooten, D., Goer, F., Pilobello, K. T., Kumar, P., et al. (2019). Assessment of striatal dopamine transporter binding in individuals with major depressive disorder: in vivo positron emission tomography and postmortem evidence. JAMA Psychiatry 76, 854-861. doi: 10.1001/jamapsychiatry.2019.0801

Pizzorusso, T., Medini, P., Berardi, N., Chierzi, S., Fawcett, J. W., and Maffei, L. (2002). Reactivation of ocular dominance plasticity in the adult visual cortex. Science 298, 1248-1251. doi: 10.1126/science.1072699

Plath, N., Ohana, O., Dammermann, B., Errington, M. L., Schmitz, D., Gross, C., et al. (2006). Arc/Arg3.1 is essential for the consolidation of synaptic plasticity and memories. Neuron 52, 437-444. doi: 10.1016/j.neuron.2006.08.024

Ploski, J. E., Pierre, V. J., Smucny, J., Park, K., Monsey, M. S., Overeem, K. A., et al. (2008). The activity-regulated cytoskeletal-associated protein (Arc/Arg3.1) is required for memory consolidation of pavlovian fear conditioning in the lateral amygdala. J. Neurosci. 28, 12383-12395. doi: 10.1523/JNEUROSCI.166208.2008

Poe, G. R., Nitz, D. A., McNaughton, B. L., and Barnes, C. A. (2000). Experiencedependent phase-reversal of hippocampal neuron firing during REM sleep. Brain Res. 855, 176-180.

Porter, S., Clark, I. M., Kevorkian, L., and Edwards, D. R. (2005). The ADAMTS metalloproteinases. Biochem. J. 386(Pt 1), 15-27. doi: 10.1042/BJ20040424

Puentes-Mestril, C., and Aton, S. J. (2017). Linking network activity to synaptic plasticity during sleep: hypotheses and recent data. Front. Neural. Circuit. 11:61. doi: 10.3389/fncir.2017.00061

Ramachandran, B., and Frey, J. U. (2009). Interfering with the actin network and its effect on long-term potentiation and synaptic tagging in hippocampal CA1 neurons in slices in vitro. J. Neurosci. 29, 12167-12173. doi: 10.1523/ JNEUROSCI.2045-09.2009

Rasch, B., and Born, J. (2013). About sleep's role in memory. Physiol. Rev. 93, 681-766. doi: 10.1152/physrev.00032.2012

Raskind, M. A., Peskind, E. R., Hoff, D. J., Hart, K. L., Holmes, H. A., Warren, D., et al. (2007). A parallel group placebo controlled study of prazosin for trauma nightmares and sleep disturbance in combat veterans with post-traumatic stress disorder. Biol. Psychiatry 61, 928-934. doi: 10.1016/j.biopsych.2006.06.032
Raven, F., Meerlo, P., Van der Zee, E. A., Abel, T., and Havekes, R. (2019). A brief period of sleep deprivation causes spine loss in the dentate gyrus of mice. Neurobiol. Learn. Mem. 160, 83-90. doi: 10.1016/j.nlm.2018.03.018

Redondo, R. L., and Morris, R. G. (2011). Making memories last: the synaptic tagging and capture hypothesis. Nat. Rev. Neurosci. 12, 17-30. doi: 10.1038/ nrn2963

Redondo, R. L., Okuno, H., Spooner, P. A., Frenguelli, B. G., Bito, H., and Morris, R. G. (2010). Synaptic tagging and capture: differential role of distinct calcium/calmodulin kinases in protein synthesis-dependent long-term potentiation. J. Neurosci. 30, 4981-4989. doi: 10.1523/JNEUROSCI.3140-09. 2010

Riga, D., Kramvis, I., Koskinen, M. K., van Bokhoven, P., van der Harst, J. E., Heistek, T. S., et al. (2017). Hippocampal extracellular matrix alterations contribute to cognitive impairment associated with a chronic depressive-like state in rats. Sci. Transl. Med. 9:8753. doi: 10.1126/scitranslmed.aai8753

Roberts, R. C., Conley, R., Kung, L., Peretti, F. J., and Chute, D. J. (1996). Reduced striatal spine size in schizophrenia: a postmortem ultrastructural study. Neuroreport 7, 1214-1218. doi: 10.1097/00001756-199604260-00024

Rosenberg, G. A., Cunningham, L. A., Wallace, J., Alexander, S., Estrada, E. Y., Grossetete, M., et al. (2001). Immunohistochemistry of matrix metalloproteinases in reperfusion injury to rat brain: activation of MMP-9 linked to stromelysin-1 and microglia in cell cultures. Brain Res. 893, 104-112. doi: 10.1016/s0006-8993(00)03294-7

Ross, R. J., Ball, W. A., Sullivan, K. A., and Caroff, S. N. (1989). Sleep disturbance as the hallmark of posttraumatic stress disorder. Am. J. Psychiatry 146, 697-707. doi: 10.1176/ajp.146.6.697

Roybal, K., Theobold, D., Graham, A., DiNieri, J. A., Russo, S. J., Krishnan, V., et al. (2007). Mania-like behavior induced by disruption of CLOCK. Proc. Natl. Acad. Sci. U.S.A. 104, 6406-6411. doi: 10.1073/pnas.0609625104

Rybakowski, J. K. (2014). Factors associated with lithium efficacy in bipolar disorder. Harv. Rev. Psychiatry 22, 353-357. doi: 10.1097/HRP. 0000000000000006

Salih, D. A., Rashid, A. J., Colas, D., de la Torre-Ubieta, L., Zhu, R. P., Morgan, A. A., et al. (2012). FoxO6 regulates memory consolidation and synaptic function. Genes Dev. 26, 2780-2801. doi: 10.1101/gad.208926.112

Samochowiec, A., Grzywacz, A., Kaczmarek, L., Bienkowski, P., Samochowiec, J., Mierzejewski, P., et al. (2010). Functional polymorphism of matrix metalloproteinase-9 (MMP-9) gene in alcohol dependence: family and case control study. Brain Res. 1327, 103-106. doi: 10.1016/j.brainres.2010.02.072

Schafer, D. P., Lehrman, E. K., Heller, C. T., and Stevens, B. (2014). An engulfment assay: a protocol to assess interactions between CNS phagocytes and neurons. J. Vis. Exp. 88:51482. doi: 10.3791/51482

Schafer, D. P., Lehrman, E. K., Kautzman, A. G., Koyama, R., Mardinly, A. R., Yamasaki, R., et al. (2012). Microglia sculpt postnatal neural circuits in an activity and complement-dependent manner. Neuron 74, 691-705. doi: 10. 1016/j.neuron.2012.03.026

Scheff, S. W., and Price, D. A. (1993). Synapse loss in the temporal lobe in Alzheimer's disease. Ann. Neurol. 33, 190-199. doi: 10.1002/ana.410330209

Schmitt, A., Koschel, J., Zink, M., Bauer, M., Sommer, C., Frank, J., et al. (2010). Gene expression of NMDA receptor subunits in the cerebellum of elderly patients with schizophrenia. Eur. Arch. Psychiatry Clin. Neurosci. 260, 101-111. doi: 10.1007/s00406-009-0017-1

Schmutz, I., Chavan, R., Ripperger, J. A., Maywood, E. S., Langwieser, N., Jurik, A., et al. (2014). A specific role for the REV-ERBalpha-controlled L-Type voltagegated calcium channel CaV1.2 in resetting the circadian clock in the late night. J. Biol. Rhythms 29, 288-298. doi: 10.1177/0748730414540453

Seidenbecher, C. I., Richter, K., Rauch, U., Fassler, R., Garner, C. C., and Gundelfinger, E. D. (1995). Brevican, a chondroitin sulfate proteoglycan of rat brain, occurs as secreted and cell surface glycosylphosphatidylinositolanchored isoforms. J. Biol. Chem. 270, 27206-27212. doi: 10.1074/jbc.270. 45.27206

Seney, M. L., Cahill, K., Enwright, J. F. III, Logan, R. W., Huo, Z., Zong, W., et al. (2019). Diurnal rhythms in gene expression in the prefrontal cortex in schizophrenia. Nat. Commun. 10:3355. doi: 10.1038/s41467-019-11335-1

Seney, M. L., Moon-Kim, S., Glausier, J. R., Hildebrand, M. A., Xue, X., Zong, W., et al. (2020). Transcriptional alterations in opioid use disorder reveal an interplay between neuroinflammation and synaptic remodeling. bioRxiv [Preprint]. doi: 10.1101/2020.09.14.296707 
Shah, A., and Lodge, D. J. (2013). A loss of hippocampal perineuronal nets produces deficits in dopamine system function: relevance to the positive symptoms of schizophrenia. Transl. Psychiatry 3:e215. doi: 10.1038/tp.2012.145

Shelton, M. A., Newman, J. T., Gu, H., Sampson, A. R., Fish, K. N., MacDonald, M. L., et al. (2015). Loss of microtubule-associated protein 2 immunoreactivity linked to dendritic spine loss in schizophrenia. Biol. Psychiatry 78, 374-385. doi: 10.1016/j.biopsych.2014.12.029

Shi, H. S., Luo, Y. X., Xue, Y. X., Wu, P., Zhu, W. L., Ding, Z. B., et al. (2011). Effects of sleep deprivation on retrieval and reconsolidation of morphine reward memory in rats. Pharmacol. Biochem. Behav. 98, 299-303. doi: 10.1016/j.pbb. 2011.01.006

Shi, W., Wei, X., Wang, X., Du, S., Liu, W., Song, J., et al. (2019). Perineuronal nets protect long-term memory by limiting activity-dependent inhibition from parvalbumin interneurons. Proc. Natl. Acad. Sci. U.S.A. 52, 27063-27073. doi: $10.1073 /$ pnas. 1902680116

Silvestri, A. J. (2005). REM sleep deprivation affects extinction of cued but not contextual fear conditioning. Physiol. Behav. 84, 343-349. doi: 10.1016/j. physbeh.2004.11.011

Sit, D. K., McGowan, J., Wiltrout, C., Diler, R. S., Dills, J. J., Luther, J., et al. (2018). Adjunctive bright light therapy for bipolar depression: a randomized doubleblind placebo-controlled trial. Am J. Psychiatry 175, 131-139. doi: 10.1176/appi. ajp.2017.16101200

Sit, D., Wisner, K. L., Hanusa, B. H., Stull, S., and Terman, M. (2007). Light therapy for bipolar disorder: a case series in women. Bipolar. Disord. 9, 918-927. doi: 10.1111/j.1399-5618.2007.00451.x

Sjoholm, L. K., Backlund, L., Cheteh, E. H., Ek, I. R., Frisen, L., Schalling, M., et al. (2010). CRY2 is associated with rapid cycling in bipolar disorder patients. PLoS One 5:e12632. doi: 10.1371/journal.pone.0012632

Skaggs, W. E., and McNaughton, B. L. (1996). Replay of neuronal firing sequences in rat hippocampus during sleep following spatial experience. Science 271, 1870-1873.

Sklar, P., Smoller, J. W., Fan, J., Ferreira, M. A., Perlis, R. H., Chambert, K., et al. (2008). Whole-genome association study of bipolar disorder. Mol. Psychiatry 13, 558-569. doi: 10.1038/sj.mp.4002151

Slaker, M. L., Jorgensen, E. T., Hegarty, D. M., Liu, X., Kong, Y., Zhang, F., et al. (2018). Cocaine exposure modulates perineuronal nets and synaptic excitability of fast-spiking interneurons in the medial prefrontal cortex. eNeuro 5:1523. doi: 10.1523/ENEURO.0221-18.2018

Slaker, M., Churchill, L., Todd, R. P., Blacktop, J. M., Zuloaga, D. G., Raber, J., et al. (2015). Removal of perineuronal nets in the medial prefrontal cortex impairs the acquisition and reconsolidation of a cocaine-induced conditioned place preference memory. J. Neurosci. 35, 4190-4202. doi: 10.1523/JNEUROSCI. 3592-14.2015

Smith, A. C., Kupchik, Y. M., Scofield, M. D., Gipson, C. D., Wiggins, A., Thomas, C. A., et al. (2014). Synaptic plasticity mediating cocaine relapse requires matrix metalloproteinases. Nat. Neurosci. 17, 1655-1657. doi: 10.1038/nn.3846

Smith, A. W., Nealey, K. A., Wright, J. W., and Walker, B. M. (2011). Plasticity associated with escalated operant ethanol self-administration during acute withdrawal in ethanol-dependent rats requires intact matrix metalloproteinase systems. Neurobiol. Learn. Mem. 96, 199-206. doi: 10.1016/j.nlm.2011.04.011

Smith, M. E. (2005). Bilateral hippocampal volume reduction in adults with post-traumatic stress disorder: a meta-analysis of structural MRI studies. Hippocampus 15, 798-807. doi: 10.1002/hipo.20102

Smith-Thomas, L. C., Stevens, J., Fok-Seang, J., Faissner, A., Rogers, J. H., and Fawcett, J. W. (1995). Increased axon regeneration in astrocytes grown in the presence of proteoglycan synthesis inhibitors. J. Cell. Sci. 108(Pt 3), 1307-1315.

Soetanto, A., Wilson, R. S., Talbot, K., Un, A., Schneider, J. A., Sobiesk, M., et al. (2010). Association of anxiety and depression with microtubule-associated protein 2- and synaptopodin-immunolabeled dendrite and spine densities in hippocampal CA3 of older humans. Arch. Gen. Psychiatry 67, 448-457. doi: 10.1001/archgenpsychiatry.2010.48

Sonntag, M., Blosa, M., Schmidt, S., Reimann, K., Blum, K., Eckrich, T., et al. (2018). Synaptic coupling of inner ear sensory cells is controlled by brevicanbased extracellular matrix baskets resembling perineuronal nets. BMC Biol. 16:99. doi: 10.1186/s12915-018-0566-8

Soria, V., Martinez-Amoros, E., Escaramis, G., Valero, J., Perez-Egea, R., Garcia, C., et al. (2010). Differential association of circadian genes with mood disorders: CRY1 and NPAS2 are associated with unipolar major depression and CLOCK and VIP with bipolar disorder. Neuropsychopharmacology 35, 1279-1289. doi: 10.1038/npp.2009.230

Spano, G. M., Banningh, S. W., Marshall, W., de Vivo, L., Bellesi, M., Loschky, S. S., et al. (2019). Sleep deprivation by exposure to novel objects increases synapse density and axon-spine interface in the hippocampal CA1 region of adolescent mice. J. Neurosci. 39, 6613-6625. doi: 10.1523/JNEUROSCI.0380-19.2019

Stefaniuk, M., Beroun, A., Lebitko, T., Markina, O., Leski, S., Meyza, K., et al. (2017). Matrix metalloproteinase- 9 and synaptic plasticity in the central amygdala in control of alcohol-seeking behavior. Biol. Psychiatry 81, 907-917. doi: 10.1016/j.biopsych.2016.12.026

Steullet, P., Cabungcal, J. H., Bukhari, S. A., Ardelt, M. I., Pantazopoulos, H., Hamati, F., et al. (2017). The thalamic reticular nucleus in schizophrenia and bipolar disorder: role of parvalbumin-expressing neuron networks and oxidative stress. Mol. Psychiatry 23, 2057-2065. doi: 10.1038/mp.2017.230

Stevens, B., and Schafer, D. P. (2018). Roles of microglia in nervous system development, plasticity, and disease. Dev. Neurobiol. 78, 559-560. doi: 10.1002/ dneu.22594

Steward, O., Wallace, C. S., Lyford, G. L., and Worley, P. F. (1998). Synaptic activation causes the mRNA for the IEG Arc to localize selectively near activated postsynaptic sites on dendrites. Neuron 21, 741-751.

Sugiyama, S., Di Nardo, A. A., Aizawa, S., Matsuo, I., Volovitch, M., Prochiantz, A., et al. (2008). Experience-dependent transfer of Otx2 homeoprotein into the visual cortex activates postnatal plasticity. Cell 134, 508-520. doi: 10.1016/j.cell. 2008.05.054

Suzuki, M., Dallaspezia, S., Locatelli, C., Lorenzi, C., Uchiyama, M., Colombo, C., et al. (2017). CLOCK gene variants associated with the discrepancy between subjective and objective severity in bipolar depression. J. Affect. Disord. 210, 14-18. doi: 10.1016/j.jad.2016.12.007

Sweet, R. A., Henteleff, R. A., Zhang, W., Sampson, A. R., and Lewis, D. A. (2009). Reduced dendritic spine density in auditory cortex of subjects with schizophrenia. Neuropsychopharmacology 34, 374-389. doi: 10.1038/npp.2008. 67

Szklarczyk, A., Lapinska, J., Rylski, M., McKay, R. D., and Kaczmarek, L. (2002). Matrix metalloproteinase- 9 undergoes expression and activation during dendritic remodeling in adult hippocampus. J. Neurosci. 22, 920-930.

Taishi, P., Sanchez, C., Wang, Y., Fang, J., Harding, J. W., and Krueger, J. M. (2001). Conditions that affect sleep alter the expression of molecules associated with synaptic plasticity. Am. J. Physiol. Regul. Integr. Comp. Physiol. 281, R839-R845. doi: 10.1152/ajpregu.2001.281.3.R839

Takayama, F., Zhang, X., Hayashi, Y., Wu, Z., and Nakanishi, H. (2017). Dysfunction in diurnal synaptic responses and social behavior abnormalities in cathepsin S-deficient mice. Biochem. Biophys. Res. Commun. 490, 447-452. doi: 10.1016/j.bbrc.2017.06.061

Terry, R. D., Masliah, E., Salmon, D. P., Butters, N., DeTeresa, R., Hill, R., et al. (1991). Physical basis of cognitive alterations in Alzheimer's disease: synapse loss is the major correlate of cognitive impairment. Ann. Neurol. 30, 572-580. doi: 10.1002/ana.410300410

Thankachan, S., Katsuki, F., McKenna, J. T., Yang, C., Shukla, C., Deisseroth, K., et al. (2019). Thalamic reticular nucleus parvalbumin neurons regulate sleep spindles and electrophysiological aspects of schizophrenia in mice. Sci. Rep. 9:3607. doi: 10.1038/s41598-019-40398-9

Thompson, C. E., Taylor, F. B., McFall, M. E., Barnes, R. F., and Raskind, M. A. (2008). Nonnightmare distressed awakenings in veterans with posttraumatic stress disorder: response to prazosin. J. Trauma Stress 21, 417-420. doi: 10.1002/ jts. 20351

Tononi, G., and Cirelli, C. (2006). Sleep function and synaptic homeostasis. Sleep Med. Rev. 10, 49-62. doi: 10.1016/j.smrv.2005.05.002

Tononi, G., and Cirelli, C. (2014). Sleep and the price of plasticity: from synaptic and cellular homeostasis to memory consolidation and integration. Neuron 81 , 12-34. doi: 10.1016/j.neuron.2013.12.025

Tottenham, N., Hare, T. A., Quinn, B. T., McCarry, T. W., Nurse, M., Gilhooly, T., et al. (2010). Prolonged institutional rearing is associated with atypically large amygdala volume and difficulties in emotion regulation. Dev. Sci. 13, 46-61. doi: 10.1111/j.1467-7687.2009.00852.x

Tremblay, L. K., Naranjo, C. A., Graham, S. J., Herrmann, N., Mayberg, H. S., Hevenor, S., et al. (2005). Functional neuroanatomical substrates of altered reward processing in major depressive disorder revealed by a dopaminergic probe. Arch. Gen. Psychiatry 62, 1228-1236. doi: 10.1001/archpsyc.62.11.1228 
Tremblay, M., Lowery, R. L., and Majewska, A. K. (2010). Microglial interactions with synapses are modulated by visual experience. PLoS Biol. 8:e1000527. doi: 10.1371/journal.pbio.1000527

Tse, D., Langston, R. F., Kakeyama, M., Bethus, I., Spooner, P. A., Wood, E. R., et al. (2007). Schemas and memory consolidation. Science 316, 76-82. doi: $10.1126 /$ science. 1135935

Tse, D., Takeuchi, T., Kakeyama, M., Kajii, Y., Okuno, H., Tohyama, C., et al. (2011). Schema-dependent gene activation and memory encoding in neocortex. Science 333, 891-895. doi: 10.1126/science. 1205274

Tsien, R. Y. (2013). Very long-term memories may be stored in the pattern of holes in the perineuronal net. Proc. Natl. Acad. Sci. U.S.A. 110, 12456-12461. doi: 10.1073/pnas.1310158110

Van Cauter, E., Leproult, R., and Plat, L. (2000). Age-related changes in slow wave sleep and REM sleep and relationship with growth hormone and cortisol levels in healthy men. JAMA 284, 861-868. doi: 10.1001/jama.284.7.861

Van den Oever, M. C., Lubbers, B. R., Goriounova, N. A., Li, K. W., Van der Schors, R. C., Loos, M., et al. (2010). Extracellular matrix plasticity and GABAergic inhibition of prefrontal cortex pyramidal cells facilitates relapse to heroin seeking. Neuropsychopharmacology 35, 2120-2133. doi: 10.1038/npp.2010.90

Vazquez-Sanroman, D. B., Monje, R. D., and Bardo, M. T. (2017). Nicotine self-administration remodels perineuronal nets in ventral tegmental area and orbitofrontal cortex in adult male rats. Addict. Biol. 22, 1743-1755. doi: 10.1111/ adb. 12437

Vecsey, C. G., Baillie, G. S., Jaganath, D., Havekes, R., Daniels, A., Wimmer, M., et al. (2009). Sleep deprivation impairs cAMP signalling in the hippocampus. Nature 461, 1122-1125. doi: 10.1038/nature08488

Videbech, P., and Ravnkilde, B. (2004). Hippocampal volume and depression: a meta-analysis of MRI studies. Am. J. Psychiatry 161, 1957-1966. doi: 10.1176/ appi.ajp.161.11.1957

Volicer, L., Harper, D. G., Manning, B. C., Goldstein, R., and Satlin, A. (2001). Sundowning and circadian rhythms in Alzheimer's disease. Am. J. Psychiatry 158, 704-711. doi: 10.1176/appi.ajp.158.5.704

Volkow, N. D., Fowler, J. S., Wang, G. J., and Swanson, J. M. (2004). Dopamine in drug abuse and addiction: results from imaging studies and treatment implications. Mol. Psychiatry 9, 557-569. doi: 10.1038/sj.mp.4001507

Volkow, N. D., Wang, G. J., Telang, F., Fowler, J. S., Logan, J., Childress, A. R., et al. (2006). Cocaine cues and dopamine in dorsal striatum: mechanism of craving in cocaine addiction. J. Neurosci. 26, 6583-6588. doi: 10.1523/JNEUROSCI.154406.2006

Vrajova, M., Stastny, F., Horacek, J., Lochman, J., Sery, O., Pekova, S., et al. (2010). Expression of the hippocampal NMDA receptor GluN1 subunit and its splicing isoforms in schizophrenia: postmortem study. Neurochem. Res. 35, 994-1002. doi: 10.1007/s11064-010-0145-z

Vyas, A., Mitra, R., Shankaranarayana Rao, B. S., and Chattarji, S. (2002). Chronic stress induces contrasting patterns of dendritic remodeling in hippocampal and amygdaloid neurons. J. Neurosci. 22, 6810-6818.

Wagner, U., Hallschmid, M., Rasch, B., and Born, J. (2006). Brief sleep after learning keeps emotional memories alive for years. Biol. Psychiatry 60, 788-790. doi: 10.1016/j.biopsych.2006.03.061

Wake, H., Moorhouse, A. J., Miyamoto, A., and Nabekura, J. (2013). Microglia: actively surveying and shaping neuronal circuit structure and function. Trends Neurosci. 36, 209-217. doi: 10.1016/j.tins.2012.11.007

Wang, D., and Teichtahl, H. (2007). Opioids, sleep architecture and sleepdisordered breathing. Sleep Med. Rev. 11, 35-46. doi: 10.1016/j.smrv.2006.03. 006

Wang, H., Katagiri, Y., McCann, T. E., Unsworth, E., Goldsmith, P., Yu, Z. X., et al. (2008). Chondroitin-4-sulfation negatively regulates axonal guidance and growth. J. Cell Sci. 121(Pt 18), 3083-3091. doi: 10.1242/jcs.032649

Wang, J. L., Lim, A. S., Chiang, W. Y., Hsieh, W. H., Lo, M. T., Schneider, J. A., et al. (2015). Suprachiasmatic neuron numbers and rest-activity circadian rhythms in older humans. Ann. Neurol. 78, 317-322. doi: 10.1002/ana.24432

Wells, A. M., Ridener, E., Bourbonais, C. A., Kim, W., Pantazopoulos, H., Carroll, F. I., et al. (2017). Effects of chronic social defeat stress on sleep and circadian rhythms are mitigated by kappa-opioid receptor antagonism. J. Neurosci. 37, 7656-7668. doi: 10.1523/JNEUROSCI.0885-17.2017
Wilson, M. A., and McNaughton, B. L. (1994). Reactivation of hippocampal ensemble memories during sleep. Science 265, 676-679.

Wirz-Justice, A. (2008). Diurnal variation of depressive symptoms. Dialog. Clin. Neurosci. 10, 337-343.

Witting, W., Kwa, I. H., Eikelenboom, P., Mirmiran, M., and Swaab, D. F. (1990). Alterations in the circadian rest-activity rhythm in aging and Alzheimer's disease. Biol. Psychiatry 27, 563-572. doi: 10.1016/0006-3223(90)90523-5

Woo, T. U., Walsh, J. P., and Benes, F. M. (2004). Density of glutamic acid decarboxylase 67 messenger RNA-containing neurons that express the $\mathrm{N}$-methyl-D-aspartate receptor subunit NR2A in the anterior cingulate cortex in schizophrenia and bipolar disorder. Arch. Gen. Psychiatry 61, 649-657. doi: 10.1001/archpsyc.61.7.649

Wright, J. W., Brown, T. E., and Harding, J. W. (2007). Inhibition of hippocampal matrix metalloproteinase-3 and -9 disrupts spatial memory. Neural Plast 2007:73813. doi: 10.1155/2007/73813

Wright, J. W., Masino, A. J., Reichert, J. R., Turner, G. D., Meighan, S. E., Meighan, P. C., et al. (2003). Ethanol-induced impairment of spatial memory and brain matrix metalloproteinases. Brain Res. 963, 252-261. doi: 10.1016/ s0006-8993(02)04036-2

Wu, Y., Sheng, W., Chen, L., Dong, H., Lee, V., Lu, F., et al. (2004). Versican V1 isoform induces neuronal differentiation and promotes neurite outgrowth. Mol. Biol. Cell 15, 2093-2104. doi: 10.1091/mbc.E03-09-0667

Xia, F., Richards, B. A., Tran, M. M., Josselyn, S. A., Takehara-Nishiuchi, K., and Frankland, P. W. (2017). Parvalbumin-positive interneurons mediate neocortical-hippocampal interactions that are necessary for memory consolidation. Elife 6:27868. doi: 10.7554/eLife.27868

Xue, Y. X., Xue, L. F., Liu, J. F., He, J., Deng, J. H., Sun, S. C., et al. (2014). Depletion of perineuronal nets in the amygdala to enhance the erasure of drug memories. J. Neurosci. 34, 6647-6658. doi: 10.1523/JNEUROSCI.5390-13.2014

Yang, G., Lai, C. S., Cichon, J., Ma, L., Li, W., and Gan, W. B. (2014). Sleep promotes branch-specific formation of dendritic spines after learning. Science 344, 1173-1178. doi: 10.1126/science. 1249098

Yang, S., Hilton, S., Alves, J. N., Saksida, L. M., Bussey, T., Matthews, R. T., et al. (2017). Antibody recognizing 4-sulfated chondroitin sulfate proteoglycans restores memory in tauopathy-induced neurodegeneration. Neurobiol. Aging 59, 197-209. doi: 10.1016/j.neurobiolaging.2017.08.002

Yin, L., Wang, J., Klein, P. S., and Lazar, M. A. (2006). Nuclear receptor Reverbalpha is a critical lithium-sensitive component of the circadian clock. Science 311, 1002-1005. doi: 10.1126/science.1121613

Yousufzai, M., Harmatz, E. S., Shah, M., Malik, M. O., and Goosens, K. A. (2018). Ghrelin is a persistent biomarker for chronic stress exposure in adolescent rats and humans. Transl. Psychiatry 8:74. doi: 10.1038/s41398-018-0135-5

Yu, Z., Chen, N., Hu, D., Chen, W., Yuan, Y., Meng, S., et al. (2020). Decreased density of perineuronal net in prelimbic cortex is linked to depressive-like behavior in young-aged rats. Front. Mol. Neurosci. 13:4. doi: 10.3389/fnmol. 2020.00004

Yuan, W., Matthews, R. T., Sandy, J. D., and Gottschall, P. E. (2002). Association between protease-specific proteolytic cleavage of brevican and synaptic loss in the dentate gyrus of kainate-treated rats. Neuroscience 114, 1091-1101. doi: 10.1016/s0306-4522(02)00347-0

Zhou, Y., Lai, C. S. W., Bai, Y., Li, W., Zhao, R., Yang, G., et al. (2020). REM sleep promotes experience-dependent dendritic spine elimination in the mouse cortex. Nat. Commun. 11:4819. doi: 10.1038/s41467-020-18592-5

Conflict of Interest: The authors declare that the research was conducted in the absence of any commercial or financial relationships that could be construed as a potential conflict of interest.

Copyright (c) 2021 Gisabella, Babu, Valeri, Rexrode and Pantazopoulos. This is an open-access article distributed under the terms of the Creative Commons Attribution License (CC BY). The use, distribution or reproduction in other forums is permitted, provided the original author(s) and the copyright owner(s) are credited and that the original publication in this journal is cited, in accordance with accepted academic practice. No use, distribution or reproduction is permitted which does not comply with these terms. 